\title{
Development of an Intense, Warm-Core Mesoscale Vortex Associated with the 8 May 2009 "Super Derecho" Convective Event*
}

\author{
CLARK EVANS \\ National Center for Atmospheric Research ${ }^{+}$Boulder, Colorado, and Atmospheric Science Group, \\ University of Wisconsin-Milwaukee, Milwaukee, Wisconsin \\ MORRIS L. WEISMAN \\ National Center for Atmospheric Research, ${ }^{+}$Boulder, Colorado \\ LANCE F. BOSART \\ State University of New York, University at Albany, Albany, New York
}

(Manuscript received 7 June 2013, in final form 17 September 2013)

\begin{abstract}
In this study, the dynamical processes contributing to warm-core meso- $\beta$-scale vortex formation associated with the 8 May 2009 "super derecho" are examined utilizing two complementary quasi-Lagrangian approaches - a circulation budget and backward trajectory analyses - applied to a fortuitous numerical simulation of the event. Warm-core meso- $\beta$-scale vortex formation occurs in a deeply moist, potentially stable environment that is conducive to the development of near-surface rotation and is somewhat atypical compared to known derecho-supporting environments.

Air parcels in the vicinity of the developing vortex primarily originate near the surface in the streamwise vorticity-rich environment, associated with the vertical wind shear of the low-level jet, immediately to the east of the eastward-moving system. Cyclonic vertical vorticity is generated along inflowing air parcels primarily by the ascent-induced tilting of streamwise vorticity and amplified primarily by ascent-induced vortex tube stretching. Descent-induced tilting of crosswise vorticity contributes to cyclonic vertical vorticity generation for the small population of air parcels in the vicinity of the developing vortex that originate to its north and west. No consistent source of preexisting vertical vorticity is present within the environment.

Cyclonic circulation on the scale of the warm-core meso- $\beta$-scale vortex increases in the lower troposphere in response to the mean vortex-scale convergence of cyclonic absolute vorticity and the local expulsion of eddy anticyclonic vertical vorticity generated within the system's cold pool. Increased cyclonic circulation is partially offset by the system-scale tilting of horizontal vorticity associated with the low-level jet, rear-inflow jet, environmental vertical wind shear, and rotational flow of the warm-core vortex itself.
\end{abstract}

\section{Introduction}

On the morning of 8 May 2009, an intense mesoscale convective system (MCS) developed over southwestern

\footnotetext{
* Supplemental information related to this paper is available at the Journals Online website: http://dx.doi.org/10.1175/JAS-D-13-0167.s1.

${ }^{+}$The National Center for Atmospheric Research is sponsored by the National Science Foundation.
}

Corresponding author address: Dr. Clark Evans, University of Wisconsin-Milwaukee, Dept. of Mathematical Sciences, P.O. Box 413, Milwaukee, WI 53201-0413.

E-mail: evans36@uwm.edu
Kansas. This MCS spawned what is colloquially known as the "super derecho" and was responsible for straightline wind gusts of up to $50 \mathrm{~m} \mathrm{~s}^{-1}$ and 26 tornadoes as it traveled from western Kansas to the southern Appalachians (Przybylinski et al. 2010; Coniglio et al. 2011). Approximately $\$ 115$ million in losses, one fatality, and four injuries have been attributed to this event (Przybylinski et al. 2010), with southern Missouri bearing the brunt of this impact. The potential development of a destructive MCS event was well forecast by both the Storm Prediction Center (Coniglio et al. 2011) as well as selected convection-permitting numerical guidance (e.g., Weisman et al. 2013) 6-24 h prior to the onset of the event. 
The formation, early evolution, and subsequent impacts of the 8 May 2009 MCS have been well studied (Lese and Martinaitis 2010; Przybylinski et al. 2010; Coniglio et al. 2011, 2012; Weisman et al. 2013). The MCS formed on the anticyclonic shear side of a strong, west-northwesterly upper-tropospheric jet streak centered across the northern Great Plains, along a northsouth gradient of thermodynamic instability across western Kansas, and in an environment of moderate to strong (15-25 $\mathrm{m} \mathrm{s}^{-1}$ between 0 and $6 \mathrm{~km}$ AGL) vertical wind shear. The MCS developed between 0700 and 0800 UTC as weak elevated convection in west-central Kansas. The convection then moved southeastward and intercepted a weak, zonally oriented lower-tropospheric baroclinic zone and the nose of an intensifying low-level jet (LLJ). This environment was not substantially different from known MCS-supporting environments (Coniglio et al. 2011; Weisman et al. 2013). Compared to other MCS events, however, the LLJ early on 8 May 2009 was unusually strong, deep, and wide, aiding in focusing ascent and promoting atmospheric destabilization (Coniglio et al. 2011). Likewise, both precipitable water values and middle-tropospheric lapse rates were unusually large with this case.

Between 0800 and 1200 UTC 8 May 2009, the MCS organized into a northeast-to-southwest-oriented bow echo containing cyclonic vertical vorticity in excess of $1 \times 10^{-3} \mathrm{~s}^{-1}$ along its leading edge and a cyclonically rotating convective cell on its northern flank at the intersection of the bow echo with the lower-tropospheric baroclinic zone (Weisman et al. 2013). With continued eastward progression, the MCS moved east of the LLJ axis into a region of weaker thermodynamic instability and vertical wind shear. Beginning around 1200 UTC, the cyclonically rotating convective cell grew upscale into an intense, warm-core meso- $\beta$-scale vortex. At its most intense, this warm-core vortex was approximately $10 \mathrm{~km}$ deep, 2-4 K warmer than its immediate environment at $700 \mathrm{hPa}$, and was associated with strong nearsurface winds of up to $50 \mathrm{~m} \mathrm{~s}^{-1}$ at the superposition of the vortex's rotational flow with the descending rearinflow jet of the MCS. Concurrently, numerous shortlived cyclonic and anticyclonic mesovortices formed along the leading edge of the MCS, well to the southeast of the warm-core vortex (Lese and Martinaitis 2010; Przybylinski et al. 2010). The strongest straight-line wind gusts and most of the 26 tornadoes spawned by this event occurred between 1200 and 1800 UTC while the warm-core vortex was at its strongest.

To the best of our knowledge, the mechanisms responsible for the development of such a rare, intense, warm-core mesoscale vortex over land in a moderately baroclinic environment in association with a parent MCS have not been documented within the literature. Consequently, it is beneficial to first examine the literature related to vortex development in convectively active environments across a wide range of scales and phenomena for relevant insight. In an environment lacking preexisting relative vertical vorticity, only the tilting of horizontal vorticity (whether environmental or buoyantly generated in nature) into the vertical can generate relative vertical vorticity. Vertical vorticity may then be amplified by the continued vertical tilting of horizontal vorticity, vortex stretching, or vortex merger and upscale vortex growth. The requisite vertical motion can be manifest in the form of mesoscale updrafts and/or downdrafts. However, the precise vertical vorticity evolution is often not the same between vertical levels, times, or convective phenomena.

Early in an MCS's life cycle, leading-line mesovortices are generated primarily by the downward tilting of coldpool-generated crosswise horizontal vorticity (Trapp and Weisman 2003; Wakimoto et al. 2006; Atkins and St. Laurent 2009). As the MCS matures, the source of horizontal vorticity transitions to that provided by the descending rear-inflow jet (Trapp and Weisman 2003; Atkins and St. Laurent 2009). Mesovortices may also form via gust front updraft tilting of cold-pool-generated horizontal vorticity along bulging line segments (Atkins and St. Laurent 2009). Mesovortices amplify in intensity by the stretching of absolute vorticity (Trapp and Weisman 2003; Wakimoto et al. 2006) and in intensity and size by merger and upscale growth (Weisman and Trapp 2003). Locally enhanced convergence and vortex tube stretching at the intersection of the MCS with a boundary can positively impact mesovortex strength (Wheatley and Trapp 2008).

Line-end mesovortices form primarily through the tilting of buoyantly generated crosswise horizontal vorticity by the system-scale ascending front-to-rear flow (Davis and Weisman 1994; Weisman and Davis 1998; Meng et al. 2012). On time scales of hours, owing to Earth's rotation, middle-tropospheric convergence of planetary vorticity leads to the preferential development of a cyclonic vortex (Weisman and Davis 1998; Trapp and Weisman 2003). Line-end mesovortices are common occurrences with MCSs, although they are generally associated with only weak boundary layer rotation, and can move rearward into the stratiform rain region of an MCS as they mature.

Diabatic heating in the stratiform rain region of MCSs promotes the development of middle-tropospheric mesoscale convective vortices (MCVs; Gamache and Houze 1982; Zhang and Fritsch 1987; Menard and Fritsch 1989; Raymond and Jiang 1990). Weak deep-layer vertical wind shear and a moist boundary layer are necessary 
conditions for near-surface rotation to form beneath an MCV (Zhang and Fritsch 1987, 1988; Menard and Fritsch 1989; Davis and Weisman 1994; Fritsch et al. 1994; Rogers and Fritsch 2001; Davis and Trier 2007; Davis and Galarneau 2009; James and Johnson 2010). Boundary layer moistening is accompanied by a change in the divergence profile to one promoting lower-tropospheric convergence and subsequent vortex amplification via system-scale stretching (Davis and Galarneau 2009). Indeed, MCV formation is thought to be dominated by the system-scale updraft stretching of both planetary and relative vorticity (Weisman and Davis 1998; Yu et al. 1999; Trapp and Weisman 2003; Conzemius and Montgomery 2009), while earlier studies suggested that mesoscale downdraft-induced stretching may also be of importance to MCV amplification in selected cases (e.g., Brandes 1990; Brandes and Ziegler 1993). On short time scales and early in the MCVs life cycle, updraft tilting may also be important (Yu et al. 1999; Conzemius and Montgomery 2009).

Likewise, weak deep-layer vertical wind shear and a moist boundary layer are necessary conditions for warm-core tropical cyclone formation (e.g., Gray 1968). The precise dynamical processes leading to tropical cyclone formation remain uncertain, however. In the "top down" paradigm (e.g., Bister and Emanuel 1997), a middle-tropospheric MCV builds downward toward the surface as the lower troposphere cools and moistens owing to the evaporation of falling precipitation. In the "bottom up" paradigm (Montgomery et al. 2006; Dunkerton et al. 2009), the merger, axisymmetrization, and upscale growth of convective-scale cyclonic vertical vorticity cores within the moisture-rich vicinity of a middle-tropospheric MCV leads to tropical cyclone formation. Here, cyclonic vertical vorticity is initially generated by the updraft-induced tilting of horizontal vorticity and is subsequently amplified by updraft-induced vortex tube stretching.

With all of this in mind, this work seeks to examine the vertical vorticity generation mechanisms and accompanying environmental conditions in order to gain insight into the development of the intense, meso- $\beta$-scale warm-core vortex associated with the 8 May 2009 super derecho. The remainder of this manuscript is structured as follows. The numerical simulation and analysis methods utilized within this study are presented in section 2. A brief overview of the simulated event is presented in section 3 . Results from the Lagrangian trajectory analyses and circulation budget conducted in this study are presented in sections 4 and 5, respectively. The key findings from this research are discussed and placed into context in section 6 .

\section{Data and methodology}

\section{a. Numerical simulation formulation and verification}

In this study, the successful real-time simulation of Weisman et al. (2013) is utilized as a proxy for the observed event. This simulation was conducted utilizing version 3.1 of the Advanced Research Weather Research and Forecasting (ARW; Skamarock et al. 2008) numerical model. The model simulation was initialized at 1200 UTC 7 May 2009 and was integrated forward for $48 \mathrm{~h}$. A single domain of $952 \times 892$ horizontal grid points centered at $37.5^{\circ} \mathrm{N}, 97.5^{\circ} \mathrm{W}$ with a horizontal grid spacing of $3 \mathrm{~km}$ was utilized. A total of 35 terrain-following vertical levels were employed within the simulation. Initial conditions were supplied by the National Oceanic and Atmospheric Administration/ Earth System Research Laboratory (NOAA/ESRL) Rapid Refresh model at a horizontal grid spacing of $13 \mathrm{~km}$ while lateral boundary conditions were obtained from 3-hourly National Centers for Environmental Prediction (NCEP) Global Forecast System (GFS) forecast data at a horizontal grid spacing of $0.5^{\circ}$ latitude and longitude.

Physical parameterization packages utilized include the Mellor-Yamada-Janjic (MYJ; Janjic 2001) planetary boundary layer parameterization and the Thompson et al. (2006) microphysical parameterization. Deep, moist convection was explicitly treated within the model simulation. The unified Noah land surface model (Chen and Dudhia 2001) was utilized to represent land surface feedback processes. Radiation processes were parameterized utilizing the Rapid Radiative Transfer Model (Mlawer et al. 1997) and Dudhia (1989) scheme for longwave and shortwave radiation, respectively. Positive-definite transport was applied to the transport of moisture fields to mitigate the positive precipitation biases that have been observed in high-resolution forecasts of deep, moist convection (Skamarock and Weisman 2009).

To a large extent, the evolution of the simulated MCS qualitatively resembles that of the observed MCS (e.g., Fig. 1 of Weisman et al. 2013). However, subtle differences exist between the simulated and observed MCSs that warrant further mention. These include the following:

- The simulated MCS developed approximately $1-2 \mathrm{~h}$ before and to the south of the observed MCS across western Kansas (not shown).

- The observed MCS acquired a north-south orientation approximately $3 \mathrm{~h}$ after its simulated counterpart, while the quasi-organized convective band east of the observed MCS acquired a west-to-east orientation 
approximately $2 \mathrm{~h}$ after its simulated counterpart [cf. Figs. 2 and 7 of Weisman et al. (2013)].

- Observed leading-line mesovortices are crudely represented by a simulated contiguous strip of cyclonic vertical velocity [Fig. 18 of Weisman et al. (2013)] owing to the coarse effective horizontal resolution of the model $(\approx 7 \Delta x$; Skamarock 2004).

- The simulated presquall mesolow, postsquall mesohigh, and wake low are each slightly more intense than in observations [cf. Figs. 3 and 8 of Weisman et al. (2013)].

Consequently, it is our belief that the model simulation bears strong qualitative resemblance to the observed event and, thus, with proper analysis, provides quantitative insight into the dynamics of warm-core meso- $\beta$-scale vortex formation associated with a physically realistic continental MCS.

\section{b. Lagrangian trajectory analyses}

The evolution of cyclonic absolute vorticity is first examined utilizing backward trajectory analyses. Backward trajectories in swarms numbering 4-16 are released every 15 min between 0700 and 1245 UTC 8 May 2009 within or immediately adjacent to the cyclonic absolute vorticity maximum (defined here as $\eta \geq 2 \times$ $10^{-3} \mathrm{~s}^{-1}$ ) associated with the simulated vortex. Backward trajectories at both $925 \mathrm{hPa}(n=136)$ and $700 \mathrm{hPa}$ $(n=148)$ that extend backward in time for $1 \mathrm{~h}$ are evaluated. Trajectory positions are updated every $1 \mathrm{~min}$ using linear interpolation between 5-min model history data and are displayed in a Lagrangian reference frame with a representative estimate simulated convective system motion $\left[c=(20,-2) \mathrm{m} \mathrm{s}^{-1}\right]$ subtracted from the horizontal wind field at each level. Storm-relative trajectory positions are insensitive to perturbations in the simulated convective system motion of $\pm 3 \mathrm{~m} \mathrm{~s}^{-1}$ in both the zonal and meridional directions (not shown). Alongtrajectory diagnostics are obtained prior to the position transformation into a storm-relative reference frame and are thus unaffected by the transformation process.

To address how vertical vorticity evolves along the backward trajectories, an along-trajectory relative vorticity budget is utilized. Mathematically, the budget takes the form

$$
\frac{d \zeta}{d t}=\omega_{H} \cdot \nabla_{H} w+(\zeta+f) \frac{\partial w}{\partial z}
$$

where $\omega_{H}$ refers to the horizontal components of the total vorticity vector. Equation (1) is identical to Eq. (3) of Weisman and Davis (1998). The terms on the righthand side of (1) represent the tilting of horizontal vorticity into the vertical and the stretching of absolute vorticity, respectively. It is frequently not possible to exactly balance this budget [i.e., the left-hand side of (1) equaling the right-hand side of (1)]. As a result, only selected representative backward trajectories are analyzed. Each selected trajectory exhibits strong quantitative agreement between the forcing-predicted and numerically simulated temporally integrated change in relative vorticity, with the forcing-predicted change in relative vorticity required to be within $20 \%$ of the numerically simulated change in relative vorticity at all analysis times.

\section{c. Circulation budget analysis}

The formation and evolution of the simulated warmcore mesoscale vortex is also examined utilizing a circulation budget analysis. Integrating an expression for the local change of relative vorticity and applying Gauss's theorem, Davis and Galarneau (2009) derive an expression for the change of circulation about the perimeter of an arbitrarily shaped closed region on an isobaric surface. This expression is given by their (4); that is,

$$
\begin{aligned}
\frac{\partial C}{\partial t}= & -\bar{\eta} \tilde{\delta} A-\oint \eta^{\prime} \mathbf{v}^{\prime} \cdot \mathbf{n} d l+\oint \omega\left(\mathbf{k} \times \frac{\partial \mathbf{v}}{\partial p}\right) \cdot \mathbf{n} d l \\
& +\oint(\mathbf{k} \times \mathbf{F}) \cdot \mathbf{n} d l .
\end{aligned}
$$

Overbars (tildes) denote the average value around (within) the perimeter of the closed region. Primes (e.g., $\left.\mathbf{v}^{\prime}\right)$ denote the local perturbation of a variable from its average value around the perimeter of the closed region. The $\tilde{\delta}$ denotes the divergence of the wind components contained within the closed region, $A$ denotes the twodimensional area of the closed region on an isobaric surface, $\mathbf{F}$ is the friction vector, $\mathbf{n}$ is the unit vector locally outward normal to the horizontal boundary of the chosen closed region, $\mathbf{v}$ is the horizontal velocity vector, and $\oint$ denotes the line integral around the perimeter of the closed region. All other variables have their conventional meteorological definition.

The first through fourth terms on the right-hand side of (2) reflect the forcing upon the circulation due to the (i) mean transport of mean absolute vorticity across the perimeter of the closed region, (ii) eddy transport of perturbation absolute vorticity across the perimeter of the closed region, (iii) tilting of horizontal vortex lines by vertical motions along the perimeter of the closed region, and (iv) frictional dissipation along the perimeter of the closed region, respectively. The mean transport term can alternatively be interpreted as the stretching of mean absolute vorticity along the perimeter of the closed region. Further details behind the interpretation of each term are found in Davis and Galarneau (2009). 
(a) 08Z08MAY2009

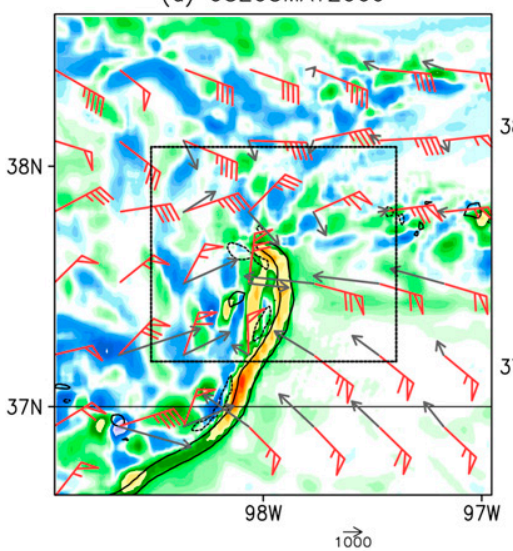

(d) 11Z08MAY2009

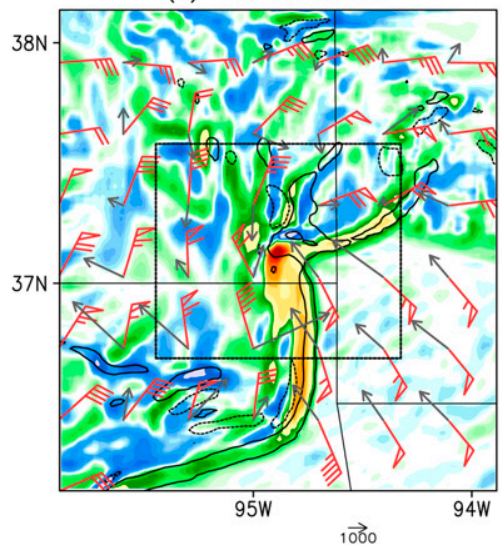

(b) 09Z08MAY2009

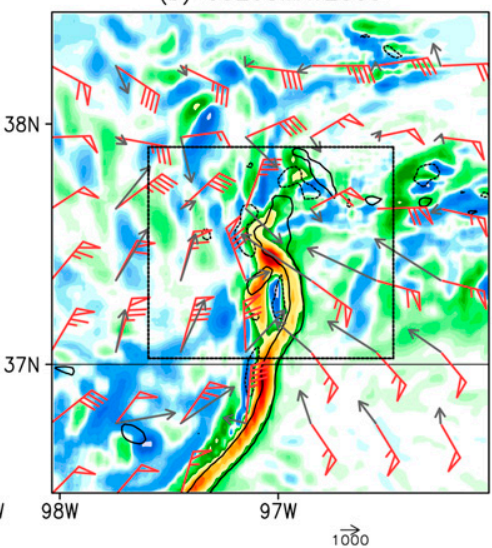

(e) 12Z08MAY2009

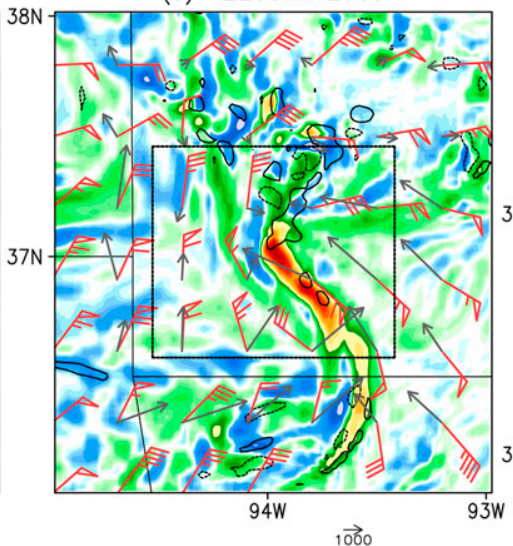

(c) 10Z08MAY2009

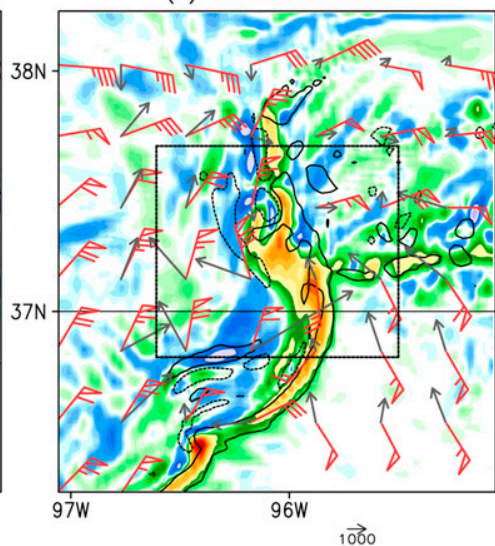

1000 900 800 $-700$

$-600$

$-500$

$\square 400$

300

$-150$ $-125$ $-100$ $-75$ 50 40 $-20$ 10 $-10$

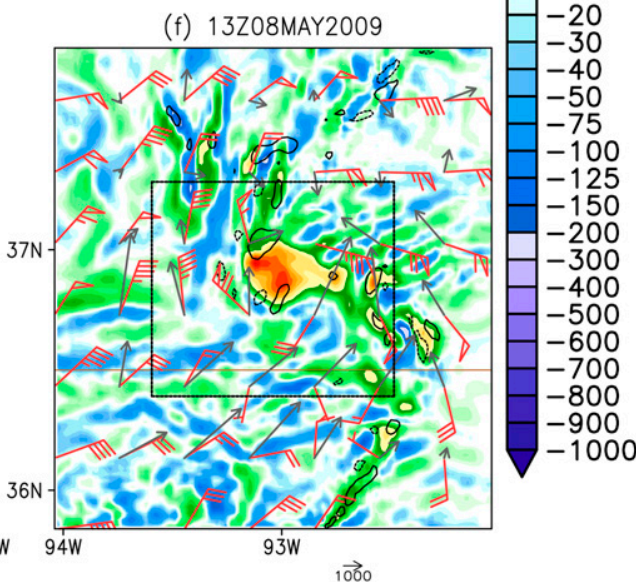

$\overrightarrow{1000}$

FIG. 1. Simulated relative vorticity $\left(\times 10^{-5} \mathrm{~s}^{-1}\right.$; color shaded), vertical motion (contoured at $\pm 1 \mathrm{~m} \mathrm{~s}^{-1}$ with negative values dashed), horizontal vorticity $\left(\times 10^{-5} \mathrm{~s}^{-1}\right.$; gray vectors), and storm-relative wind (red) (half barb: $2.5 \mathrm{~m} \mathrm{~s}^{-1}$, full barb: $5 \mathrm{~m} \mathrm{~s}^{-1}$, flag: $25 \mathrm{~m} \mathrm{~s}^{-1}$ ) at $925 \mathrm{hPa}$ at (a) 0800, (b) 0900, (c) 1000, (d) 1100, (e) 1200, and (f) 1300 UTC 8 May 2009. The storm-relative wind at each time is computed with respect to a constant-storm-motion estimate of $(20,-2) \mathrm{m} \mathrm{s}^{-1}$. The horizontal vorticity reference vector is depicted in the lower right of each panel. The black dotted square in each panel denotes the $100 \mathrm{~km} \times 100 \mathrm{~km}$ box utilized for the circulation budget analyses described in section $2 \mathrm{~b}$.

The mean and perturbation absolute vorticity in the mean and eddy transport terms of (2) can be separated into their relative and planetary vorticity components; that is,

$$
\begin{aligned}
\frac{\partial C}{\partial t}= & -\bar{f} \tilde{\delta} A-\overline{\boldsymbol{s}} \tilde{\delta} A-\oint f^{\prime} \mathbf{v}^{\prime} \cdot \mathbf{n} d l-\oint s^{\prime} \mathbf{v}^{\prime} \cdot \mathbf{n} d l \\
& +\oint \omega\left(\mathbf{k} \times \frac{\partial \mathbf{v}}{\partial p}\right) \cdot \mathbf{n} d l+\oint(\mathbf{k} \times \mathbf{F}) \cdot \mathbf{n} d l .
\end{aligned}
$$

For a closed region of small meridional extent, the third term on the right-hand side of (3) is more than two orders of magnitude smaller than the other forcing terms. With this in mind, and neglecting friction, (3) simplifies to

$$
\frac{\partial C}{\partial t}=-\bar{f} \tilde{\delta} A-\bar{s} \tilde{\delta} A-\oint s^{\prime} \mathbf{v}^{\prime} \cdot \mathbf{n} d l+\oint \omega\left(\mathbf{k} \times \frac{\partial \mathbf{v}}{\partial p}\right) \cdot \mathbf{n} d l .
$$

This equation thus allows for the assessment of mean and eddy (Davis and Galarneau 2009) as well as planetary and relative vorticity (Trapp and Weisman 2003) contributions to circulation changes within a specified closed region. The forcing terms on the right-hand side of (4) represent the mean transport of mean planetary vorticity, mean transport of mean relative vorticity, eddy transport of perturbation relative vorticity, and tilting, respectively. As before, the mean transport terms may alternatively be interpreted as the stretching of mean planetary vorticity and the stretching of mean relative vorticity, respectively.

Note that the wind field utilized in the computation of the circulation budget is the storm-relative wind field. In (4), all terms are Galilean invariant except for the eddy transport term, which is highly sensitive to the storm motion estimate. As the simulated vortex does not move at a constant speed, an instantaneous, nonconstant storm 


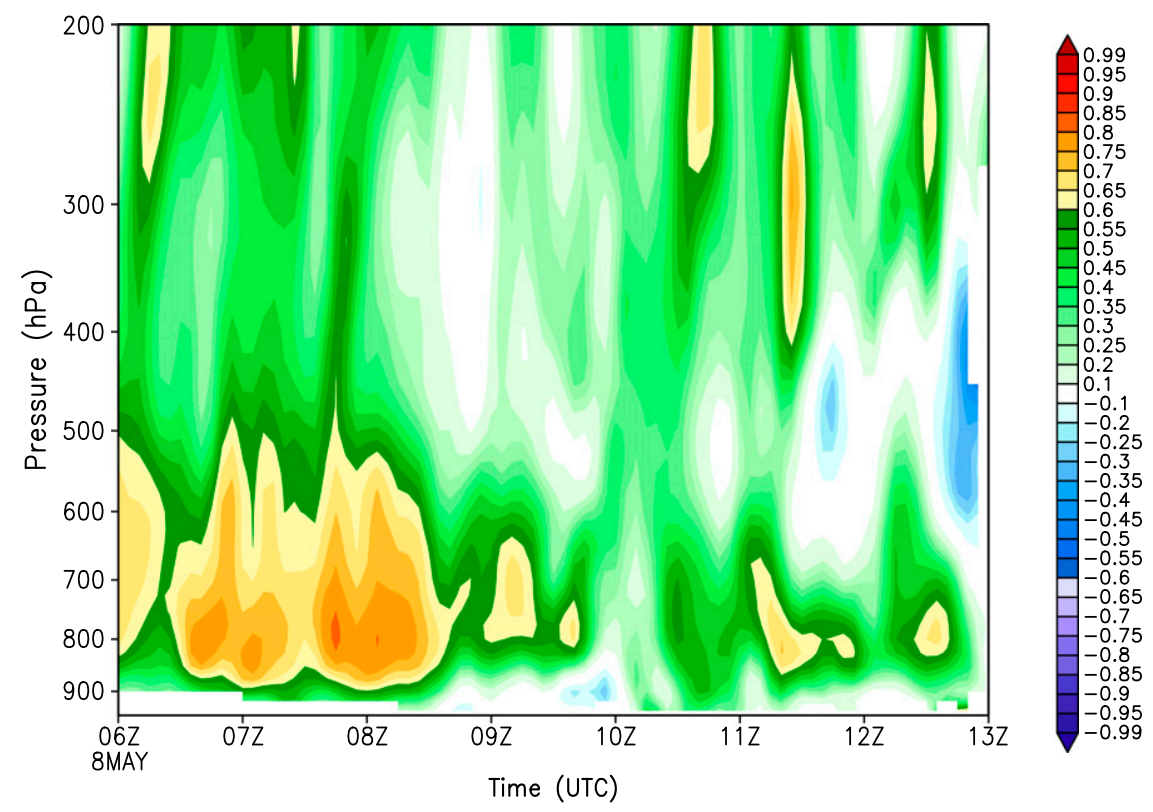

FIG. 2. Time-height cross section of the simulated area-averaged linear correlation coefficient between relative vorticity and vertical velocity. Only vertical velocity values $>1 \mathrm{~m} \mathrm{~s}^{-1}$ are considered when computing the correlation coefficient. A $20 \mathrm{~km} \times 20 \mathrm{~km}$ box centered on the nascent meso- $\beta$-scale vortex (i.e., the cyclonically rotating convective cell on the northern extent of the parent MCS) is used to compute the area average. The vertical axis extends from 950 to $200 \mathrm{hPa}$ while the temporal axis extends from 0600 to 1300 UTC 8 May 2009.

motion estimate (rounded to the nearest meter per second) is utilized to compute the storm-relative wind field. This improves the accuracy of the eddy transport term in situations where system motion deviated by more than $3 \mathrm{~m} \mathrm{~s}^{-1}$ from a representative constant system motion estimate and/or when one or more local maxima in perturbation vertical vorticity were collocated with perturbation horizontal velocity normal to the chosen analysis box.

A square box with side length equal to $100 \mathrm{~km}$, or the approximate scale of the simulated vortex, is utilized as the closed circuit for circulation tendency computation. The analysis is insensitive to small changes in the side length on the order of tens of kilometers (not shown). To account for vortex position sensitivity and uncertainty, an ensemble of analysis boxes is utilized. Following Davis and Galarneau (2009), the center of the box is perturbed by between \pm 1 and 5 grid points $( \pm 3-15 \mathrm{~km})$ in the zonal and meridional directions from its control location, resulting in an ensemble of 121 boxes at each analysis time. All terms of the circulation budget are first computed for each box, after which the terms are averaged over all 121 boxes.

At each analysis time, the control analysis box is centered upon the subjectively tracked center of the 850-hPa relative vorticity maximum associated with the simulated northern line-end vortex. The 850 -hPa level is chosen by virtue of that being where the simulated vortex is strongest (Weisman et al. 2013). As the vortex exhibits minimal vertical tilt, however, there is little sensitivity in the vortex location to the choice of tracking level (not shown). The simulated vortex is tracked subjectively because given that objective measures of feature tracking occasionally result in position estimates along the vertical vorticity-rich bow echo.

Budget calculations are carried out between 0600 and 1800 UTC 8 May 2009 utilizing postprocessed ARW model output over a history interval of $15 \mathrm{~min}$. All calculations are conducted between 900 and $400 \mathrm{hPa}$ $(\Delta p=25 \mathrm{hPa})$ and all partial derivatives are computed using centered finite differences. To facilitate interpretation, circulation $\left(\mathrm{m}^{2} \mathrm{~s}^{-1}\right)$ and its time tendency $\left(\mathrm{m}^{2} \mathrm{~s}^{-2}\right)$ are described in terms of the area-averaged absolute vorticity $\left(\mathrm{s}^{-1}\right)$ and its time tendency $\left(\mathrm{s}^{-1} \mathrm{~h}^{-1}\right)$. This is accomplished by dividing the circulation by the area of the analysis box $\left(10^{10} \mathrm{~m}^{2}\right)$ and, for its time tendency, multiplying the result by $3600 \mathrm{sh}^{-1}$.

\section{Overview of the simulated event}

Comprehensive descriptions of the basic structure of the simulated meso- $\beta$-scale warm-core vortex and its environment are provided by Weisman et al. (2013). In the following, we emphasize the simulated lower- to middle-tropospheric structure of vertical vorticity, its 
(a) 08Z08MAY2009

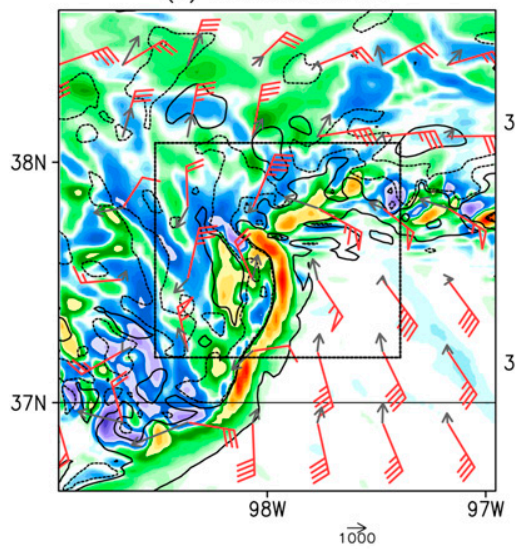

(d) 11Z08MAY2009

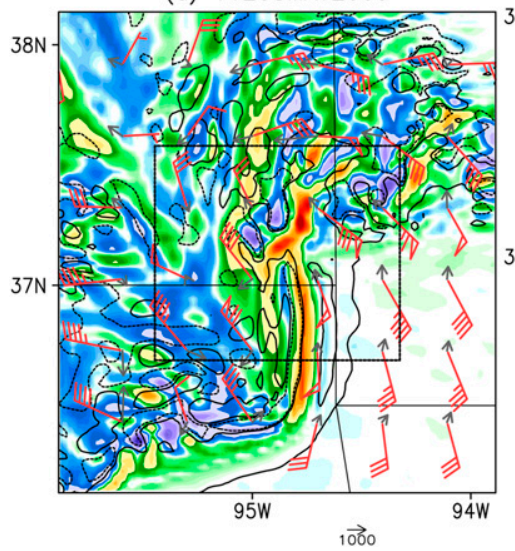

(b) O9ZO8MAY2009

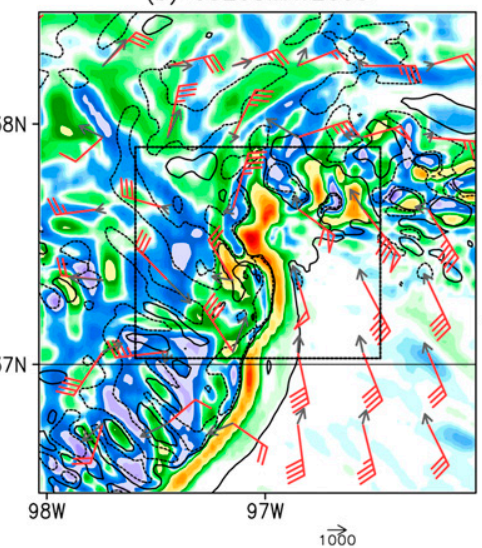

(e) 12Z08MAY2009

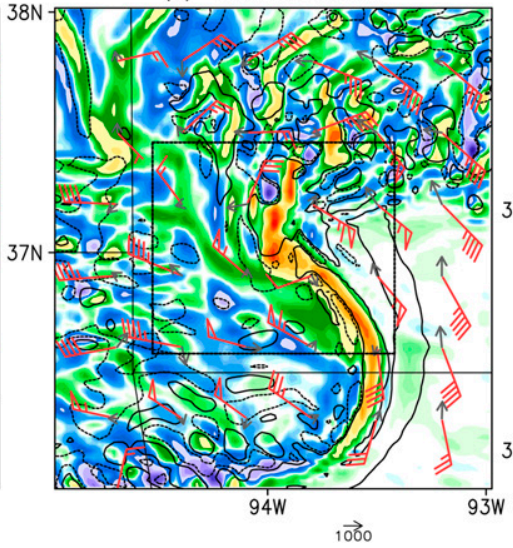

(c) 10Z08MAY2009

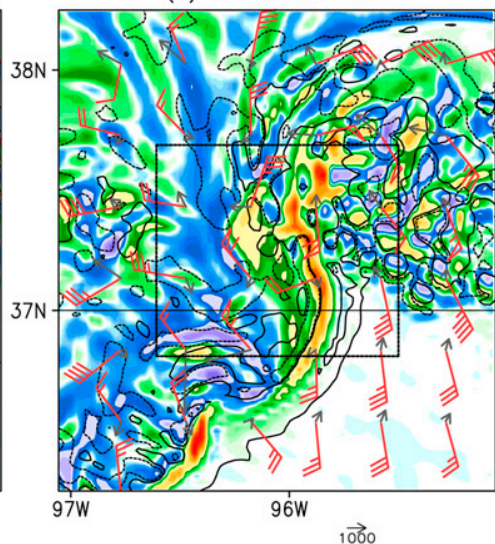

(f) 13Z08MAY2009

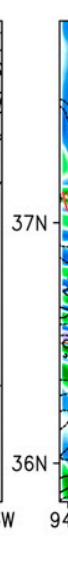

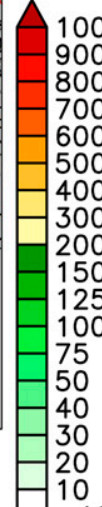

800

700

600 500 400 300 200 50 25 100 50 40 $\underbrace{20}_{\substack{10 \\-10}}$ $-20$ -30
-40 $-50$ $-100$ $-125$ $-150$

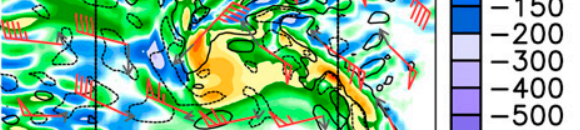

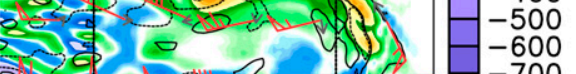

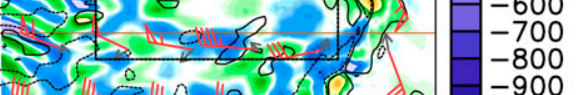

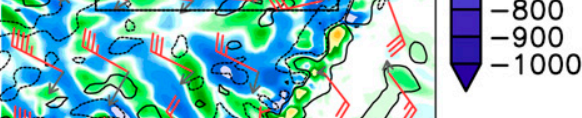

FIG. 3. As in Fig. 1, but at $700 \mathrm{hPa}$. temporal evolution, and the salient environmental conditions in the immediate proximity of the MCS and meso$\beta$-scale warm-core vortex.

At $925 \mathrm{hPa}$, the northern end of the squall line associated with the parent MCS is characterized by a cyclonically rotating convective cell (Fig. 1). This convective cell weakens around 1000 UTC (Fig. 1c) but reorganizes shortly thereafter (Fig. 1d). Vertical velocity and cyclonic relative vorticity are generally well correlated with both this convective cell (Fig. 2) and the MCS's accompanying squall line. The transition of the system from a line-dominant to a vortex-dominant structure is accompanied by the weakening of the squall line as it surges eastward between 1100 and 1300 UTC (Figs. 1d-f). The MCS's environment is characterized primarily by crosswise vorticity except to its south and east, where the environment is characterized by streamwise vorticity, particularly prior to 1200 UTC. Here, storm-relative inflow in excess of $25 \mathrm{~m} \mathrm{~s}^{-1}$ and horizontal vorticity in excess of $1 \times 10^{-2} \mathrm{~s}^{-1}$ are found. Storm-relative inflow is associated with the eastward motion of the MCS in the presence of a strong southwesterly low-level jet [e.g., Figs. 10a-c of Weisman et al. (2013)]. Horizontal vorticity is associated primarily with the vertical shear of the low-level jet (not shown). Such a kinematic configuration most closely resembles the "upstream trough" pattern of Coniglio et al. (2004), albeit with a stronger and wider low-level jet in this case.

The evolution at $700 \mathrm{hPa}$ (Fig. 3) is similar to that at $925 \mathrm{hPa}$ with only minor differences. The magnitudes of both storm-relative inflow and horizontal vorticity are weaker at 700 than at $925 \mathrm{hPa}$. Abundant couplets of cyclonic and anticyclonic relative vorticity are present to the east and north of the system at $700 \mathrm{hPa}$. These couplets are well correlated with horizontal gradients of vertical motion associated with convective-scale ascent and descent, implying that they are generated by the tilting of horizontal vorticity into the vertical by vertical motions associated with widespread elevated deep, moist convection [e.g., Figs. 12a,c of Weisman et al. 


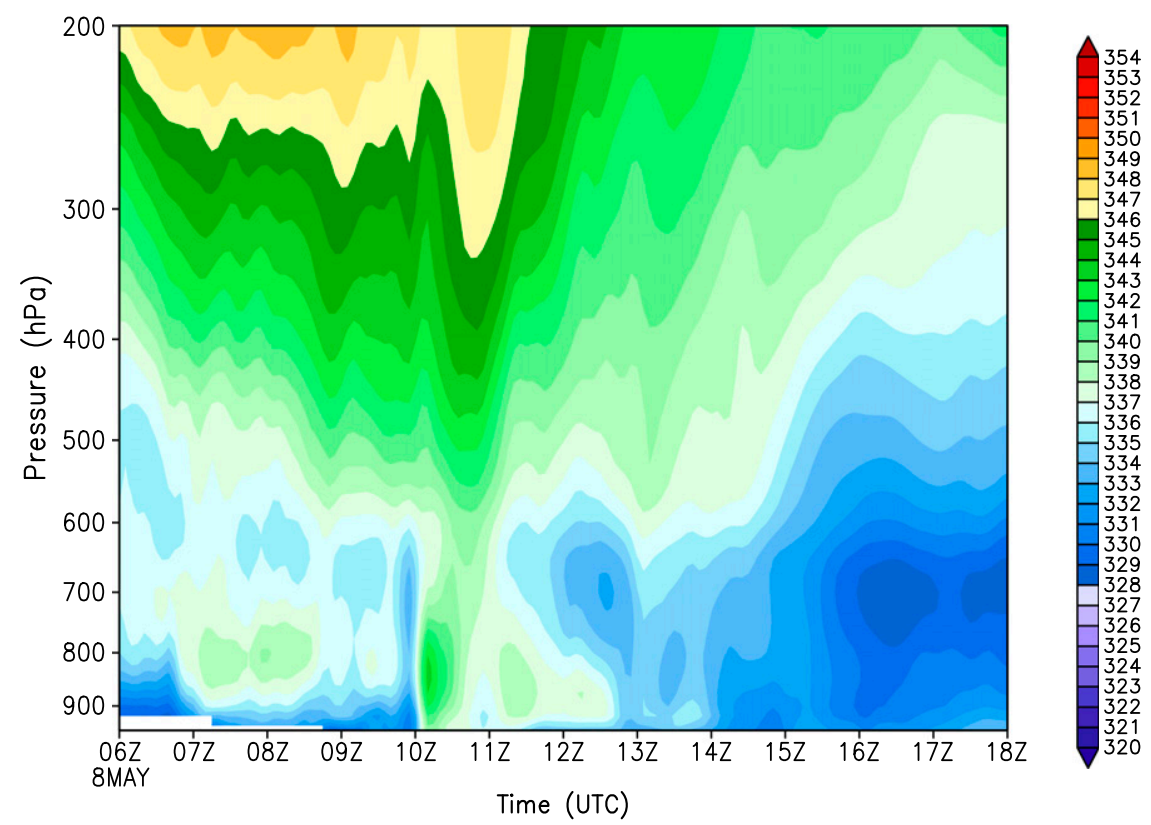

FIG. 4. As in Fig. 2, but for equivalent potential temperature (K) and within a $40 \mathrm{~km} \times 40 \mathrm{~km}$ box centered on the nascent meso- $\beta$-scale vortex The temporal axis extends from 0600 to 1800 UTC 8 May 2009.

(2013)]. As compared to $925 \mathrm{hPa}$, there is greater anticyclonic relative vorticity within the MCS's cold pool at $700 \mathrm{hPa}$ prior to $1100 \mathrm{UTC}$. The reduction in anticyclonic relative vorticity found within the system's cold pool at and after 1100 UTC is consistent with the weakening of the cold pool described by Weisman et al. (2013). Finally, ascent along the squall line associated with the parent MCS is more persistent at $700 \mathrm{hPa}$, although it too weakens as the squall line itself weakens.

The environment at the northern extent of the MCS is characterized by relatively moist and potentially stable conditions (Fig. 4). This result is insensitive to minor changes in the area over which the area average is computed (not shown). Prior to 1000 UTC, equivalent potential temperature is lowest at and near the surface. Moistening of the lower troposphere between 1000 and 1300 UTC decreases the magnitude of the equivalent potential temperature difference between the surface and middle troposphere by approximately $5 \mathrm{~K}$. It should be noted, however, that the "moist neutral" profile illustrated by previous researchers (e.g., Davis and Galarneau 2009) to be favorable for surface cyclone development is never fully achieved except at isolated locations within the analysis region depicted in Fig. 4. After the meso- $\beta$-scale vortex develops (i.e., around 1200 UTC), potential stability is maintained as equivalent potential temperature gradually decreases throughout the troposphere.

\section{Results: Lagrangian trajectory analysis}

\section{a. Overview}

In the storm-relative reference frame (i.e., centered on the release point of each backward trajectory at or adjacent to the vertical vorticity maximum), nearly all backward trajectories at both 700 (Fig. 5a) and $925 \mathrm{hPa}$ (Fig. 5b) originate east of the MCS, with backward trajectories released at $925 \mathrm{hPa}$ originating at slightly higher latitudes than at $700 \mathrm{hPa}$. There is minimal sensitivity in backward trajectory path to release time (cf. light to dark blue paths in Figs. 5a,b) and to small perturbations in trajectory release altitude (not shown).

A majority of trajectories released at both 700 and $925 \mathrm{hPa}$ originate within the streamwise vorticity-rich boundary layer (Figs. 5c,d). Recall that the environment east of the MCS is characterized by abundant streamwise vorticity along and to the south of a weak lowertropospheric baroclinic zone (Figs. 1 and 2). Only within the 5-10 min prior to trajectory release time do trajectories ascend to either isobaric surface. The remaining backward trajectories originate at higher altitudes, particularly at later times, with many at $925 \mathrm{hPa}$ approaching their release location from the north-northwest. This trajectory evolution is discussed further in section $4 \mathrm{c}$.

Dahl et al. (2012) demonstrated that backward trajectories released within near-surface mesocyclones associated with supercell thunderstorms, associated with 
(a) $700 \mathrm{hPa}$

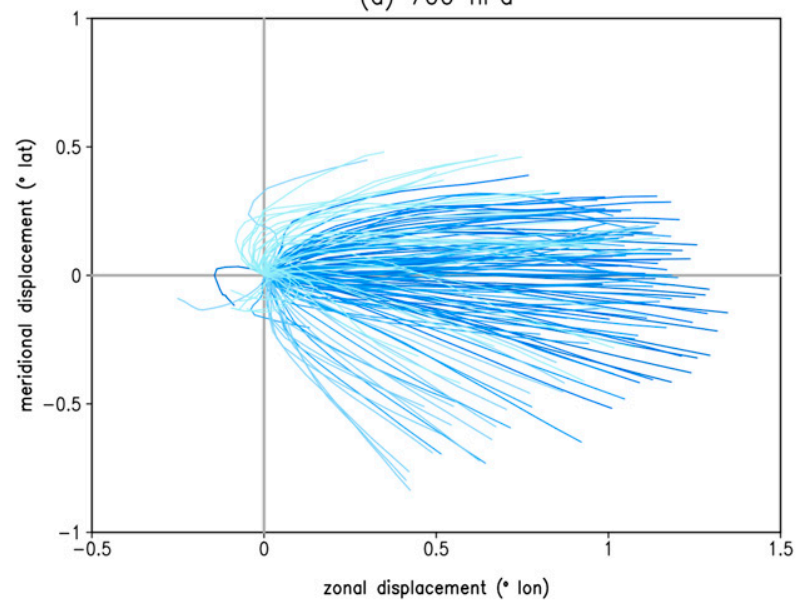

(c) $700 \mathrm{hPa}$

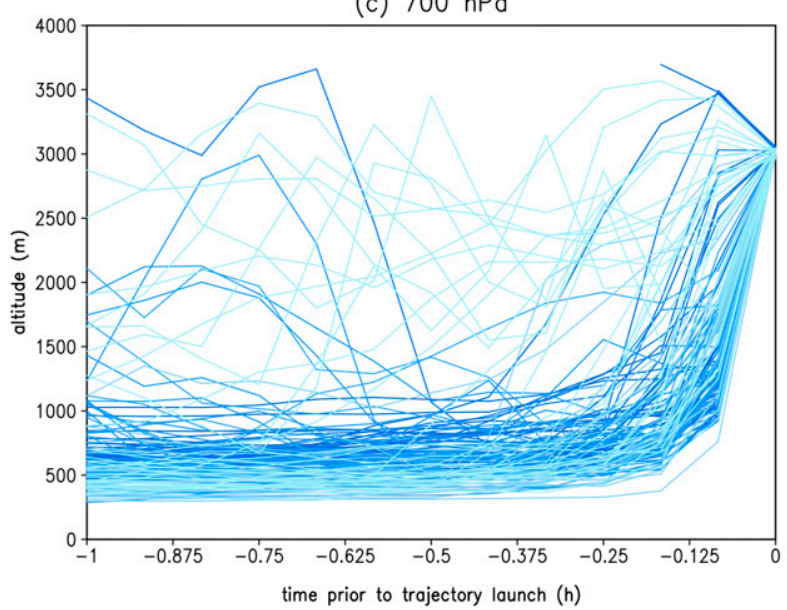

(b) $925 \mathrm{hPa}$

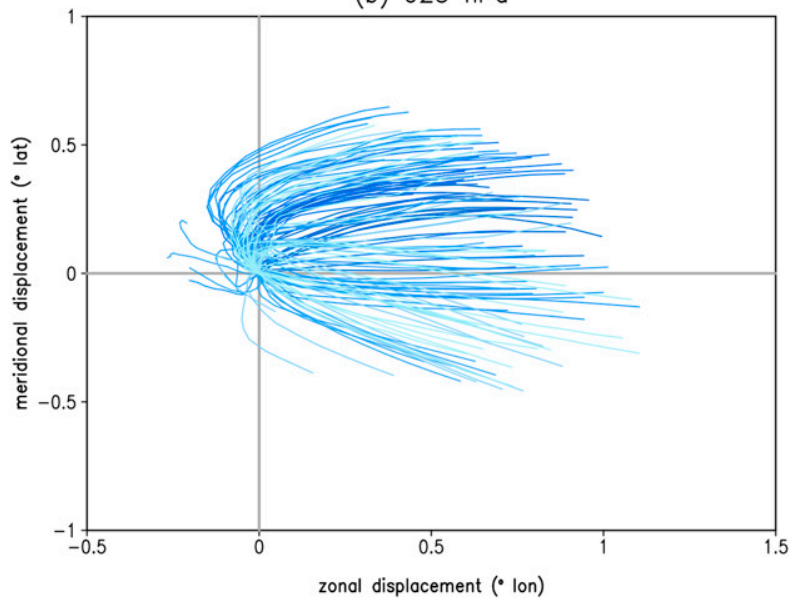

(d) $925 \mathrm{hPa}$

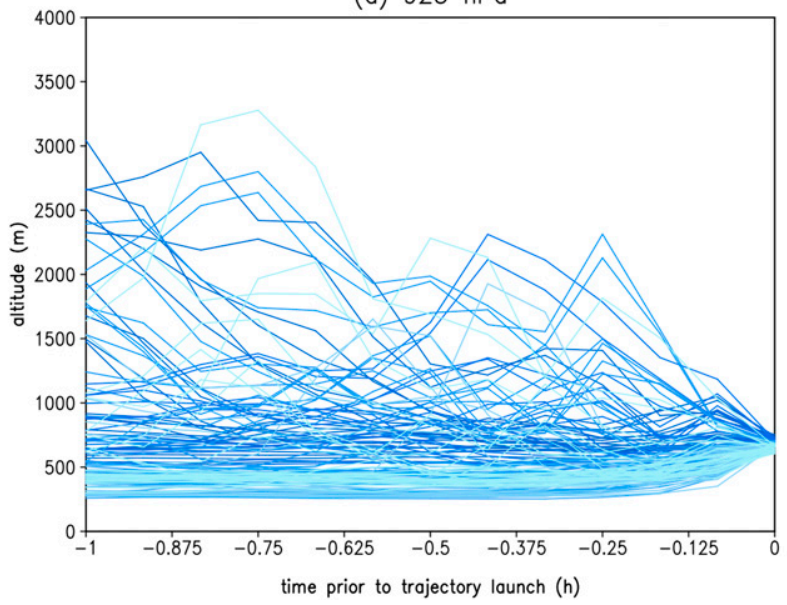

FIG. 5. (a),(b) Backward trajectories relative to a system motion of $c=(20,-2) \mathrm{m} \mathrm{s}^{-1}$, depicted in a reference frame centered on the release point of each trajectory. (c),(d) The altitude $(\mathrm{m})$ of each backward trajectory is depicted in a reference frame relative to the time at which the backward trajectory is released $(t=0 \mathrm{~h})$. Backward trajectories released at (left) $700 \mathrm{hPa}(n=148)$ and (right) $925 \mathrm{hPa}(n=$ 136). Backward trajectories are released every $15 \mathrm{~min}$ between 0700 and 1245 UTC, with darker (lighter) lines denoting earlier (later) release times.

strong three-dimensional velocity gradients, can be biased toward inflow region trajectories. Consequently, given the presence of strong environmental and vortexrelated cyclonic curvature (e.g., Figs. 1 and 2) and the relatively coarse spatiotemporal discretization of the model, it follows that the backward trajectory population in this work may also be biased toward inflow region trajectories. For evaluation purposes, forward trajectories are released from the backward trajectory termination locations. Excellent agreement between the two populations of trajectories is noted at $700 \mathrm{hPa}$; however, at $925 \mathrm{hPa}$, approximately $15 \%$ of forward trajectories ascend within convective updrafts in the 5-15 min prior to their termination (see online supplement). Nevertheless, the overall agreement in the three-dimensional evolutions of both trajectory populations provides some measure of confidence in the robustness of the backward trajectory population. Further in-depth investigation is necessary, however, to quantify the precise degree of nonrepresentativeness, if any, of the backward trajectory population.

\section{b. Balancing trajectory statistics}

Most of the 284 total backward trajectories evaluated for this study exhibit meaningful qualitative balance between the budget-predicted and actual (or numerically simulated) change in vertical vorticity along the trajectory. However, only 72 backward trajectories are deemed to exhibit quantitative balance (to within the $20 \%$ threshold described in section $2 \mathrm{~b}$ ) between the 


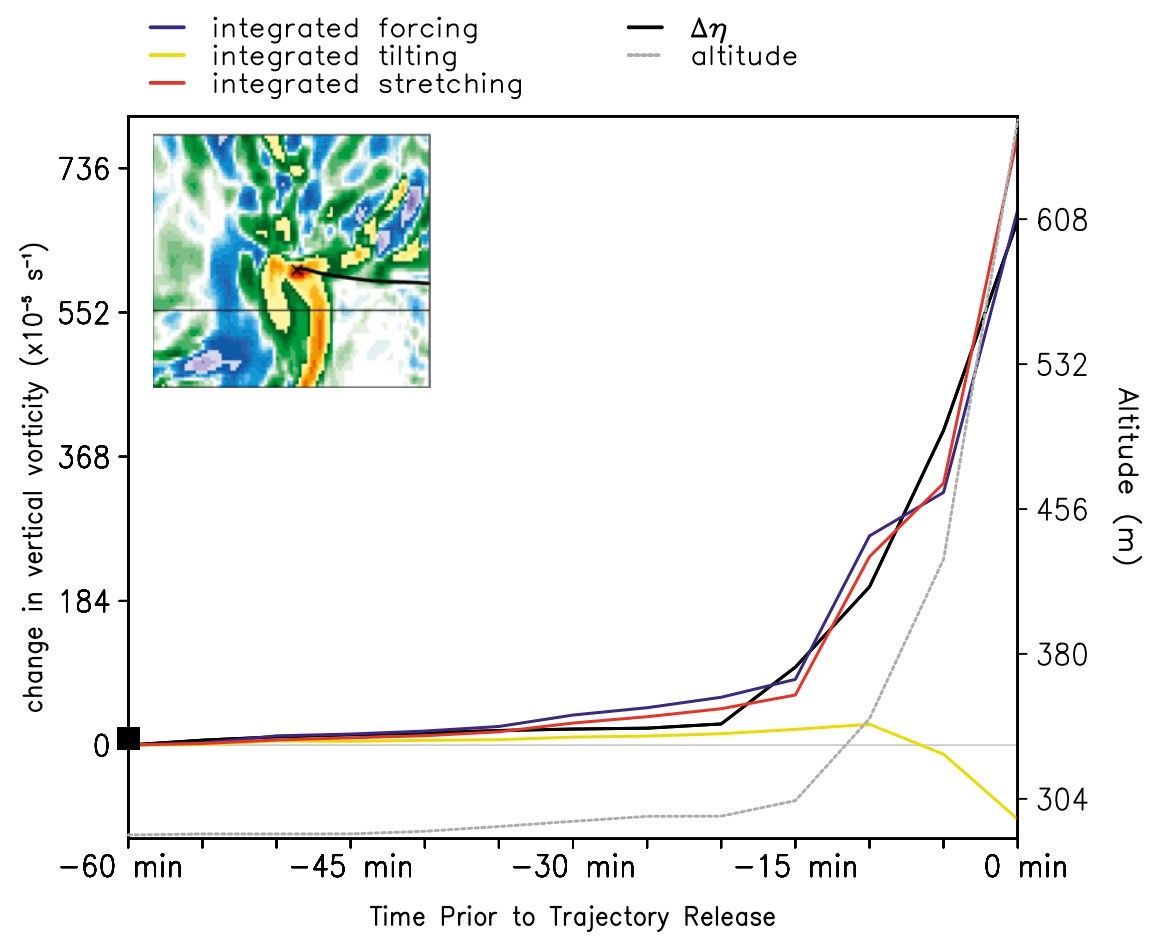

FIG. 6. Vertical vorticity forcing evolution for a representative backward trajectory, released at $925 \mathrm{hPa}$ at $1015 \mathrm{UTC}$, within the ascent-driven stretching trajectory population. The thick black line denotes the change in relative vorticity, defined as $\zeta-\zeta\left(t_{0}\right)\left(\times 10^{-5} \mathrm{~s}^{-1}\right)$, along the inflowing backward trajectory. The yellow and red lines denote the temporally integrated forcing $\left(\times 10^{-5} \mathrm{~s}^{-1}\right)$ due to tilting and vortex tube stretching, respectively. The blue line denotes the temporally integrated total forcing $\left(\times 10^{-5} \mathrm{~s}^{-1}\right)$. A perfectly balancing budget is characterized by overlapping blue and black lines. The black filled square at the backward-trajectory origination time denotes the initial value of absolute vorticity $\left(\times 10^{-5} \mathrm{~s}^{-1}\right)$. The backward trajectory's altitude $(\mathrm{m})$ is denoted by the dashed gray line. The inset depicts 925 -hPa relative vorticity $\left(\times 10^{-5} \mathrm{~s}^{-1}\right.$, shaded per the color legend in Figs. 1 and 2; warm colors denote positive values) at 1015 UTC over a $1.5^{\circ}$ longitude by $1^{\circ}$ latitude region centered on the backwardtrajectory release point (black cross). The storm-relative path of the backward trajectory is illustrated by the curving black line.

budget-predicted and actual along-trajectory change in vertical vorticity along the entirety of the trajectory path. Of the 72 balancing trajectories, 42 (30) terminate at $925(700) \mathrm{hPa}$. These represent approximately $30 \%$ and $20 \%$, respectively, of the total number of trajectories released at each level.

Along balancing inflowing trajectories, there exist three distinct trajectory populations. The first population is characterized primarily by vertical vorticity amplification via updraft-induced vortex tube stretching and is referred to here as the "ascent-driven stretching" population. A total of 44 balancing trajectories constitute this population, with 24 (20) released at $925(700) \mathrm{hPa}$. The second population is characterized primarily by initial vertical vorticity generation and continued amplification due to updraft-induced tilting and is referred to here as the "ascent-driven tilting" population. A total of 13 balancing trajectories constitute this population, with
3 (10) released at $925(700) \mathrm{hPa}$. The third and final population is characterized primarily by descending parcels and is referred to here as the "descent-dominant tilting" population. A total of 15 balancing trajectories comprise this population, with all 15 released at $925 \mathrm{hPa}$.

\section{c. Representative backward trajectory evolutions}

\section{1) ASCENT-DRIVEN STRETCHING}

Of the 44 backward trajectories constituting the ascentdriven stretching trajectory population, 13 ( 4 at $700 \mathrm{hPa}$ and 9 at $925 \mathrm{hPa}$ ) were released from the vertical vorticity maximum itself while $31(16$ at $700 \mathrm{hPa}$ and 15 at $925 \mathrm{hPa}$ ) were released immediately adjacent to the vertical vorticity maximum. A representative backward trajectory from this population is depicted within Fig. 6. Backward trajectories within this population ascending to either 925 or $700 \mathrm{hPa}$ originate within the 
(a) 08Z08MAY2009

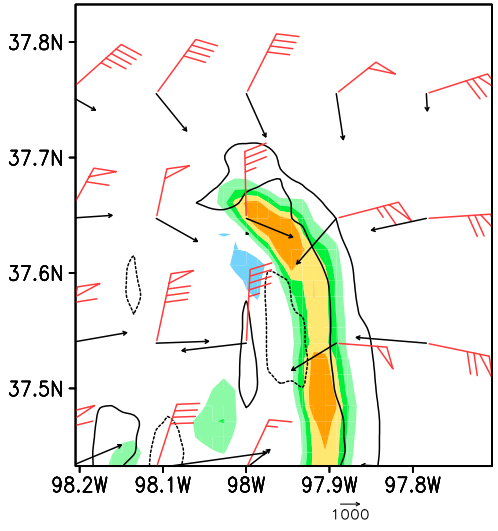

(d) 11Z08MAY2009

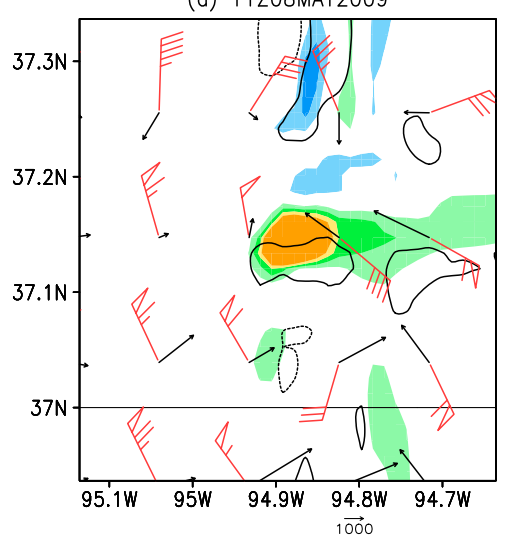

(b) 09Z08MAY2009

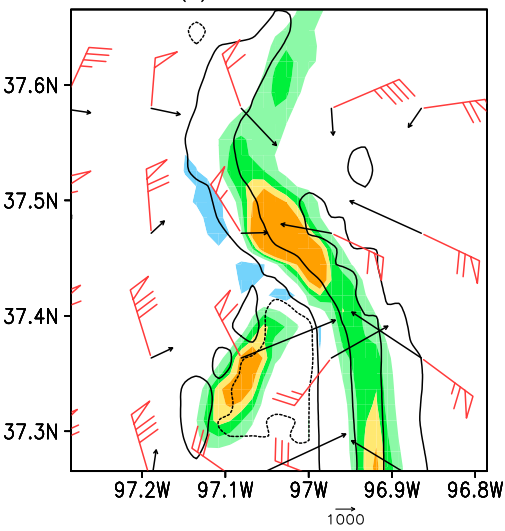

(c) 10Z08MAY2009

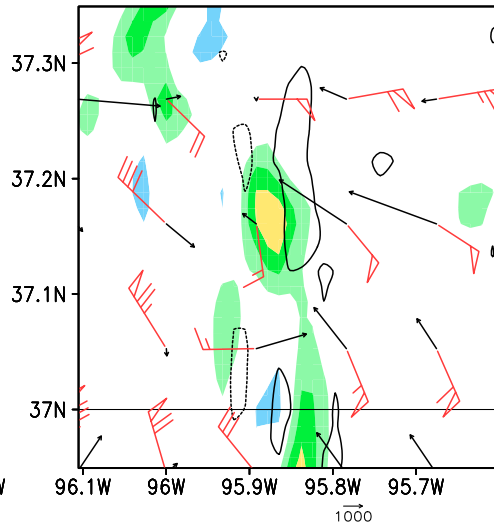

(f) 13Z08MAY2009

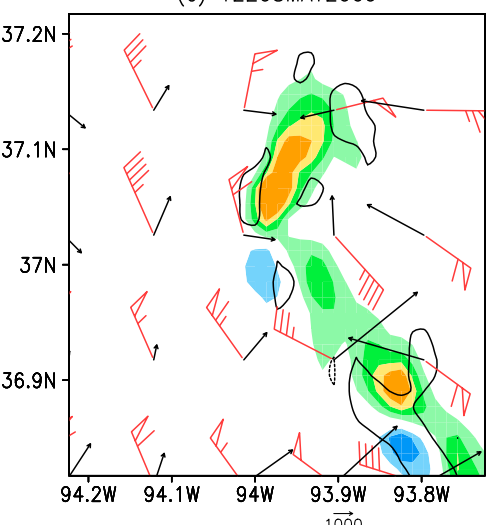

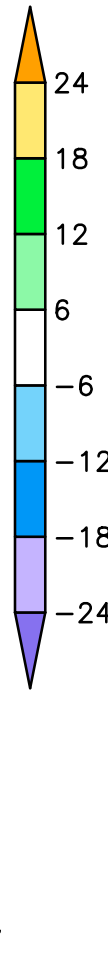

FIG. 7. As in Fig. 1, but for simulated vortex tube stretching $\left[\times 10^{-3} \mathrm{~s}^{-1}(15 \mathrm{~min})^{-1}\right.$; color shaded], tilting [contours at $\pm 6 \times 10^{-3} \mathrm{~s}^{-1}$ $(15 \mathrm{~min})^{-1}$ ], and horizontal vorticity $\left(\times 10^{-5} \mathrm{~s}^{-1}\right.$; black vectors $)$. Each panel encompasses a $0.4^{\circ}$ latitude by $0.5^{\circ}$ longitude region centered on the objectively identified nascent meso- $\beta$-scale warm-core vortex.

boundary layer to the east, in the storm-relative sense, of the MCS. These trajectories contain no meaningful initial vertical vorticity, implying that there is no preexisting source of vertical vorticity contributing to meso- $\beta$-scale vortex development in the context of this trajectory population.

Cyclonic vertical vorticity is initially generated by weak updraft-induced tilting. This occurs as rearwardmoving air parcels encounter the eastern periphery of the mesoscale updraft found at the northern extent of the MCS (Fig. 7). In the $0-15$ min prior to trajectory release time, cyclonic vertical vorticity is amplified by updraft-induced vortex tube stretching as rearwardmoving air parcels become better collocated with the core of the mesoscale updraft at the northern extent of the MCS (Fig. 7). This vertical vorticity forcing evolution is consistent with air parcels that contain substantial streamwise vorticity, as expected given the streamwise vorticity-rich environment in which they reside (Fig. 1) and the spatial patterns of tilting and stretching illustrated in Fig. 7.

Though the focus of this analysis is upon the generation and subsequent amplification of vertical vorticity associated with the developing meso- $\beta$-scale warmcore vortex, it should be noted that the ascent-driven stretching of vertically-tilted environmental streamwise vorticity is also the predominant vertical vorticity forcing for backward trajectories released within the parent MCS's squall line extending to the south from the vortex. Here, backward trajectories originate ahead of the squall line and, in the storm-relative sense, move rearward toward the squall line (not shown). Cyclonic vertical vorticity is generated by tilting along the eastern periphery of the leading-line updraft and is subsequently amplified by stretching in the updraft core (Fig. 7), which is well correlated with the cyclonic vertical vorticity maximum associated with the squall line (e.g., Figs. 1 and 2). 


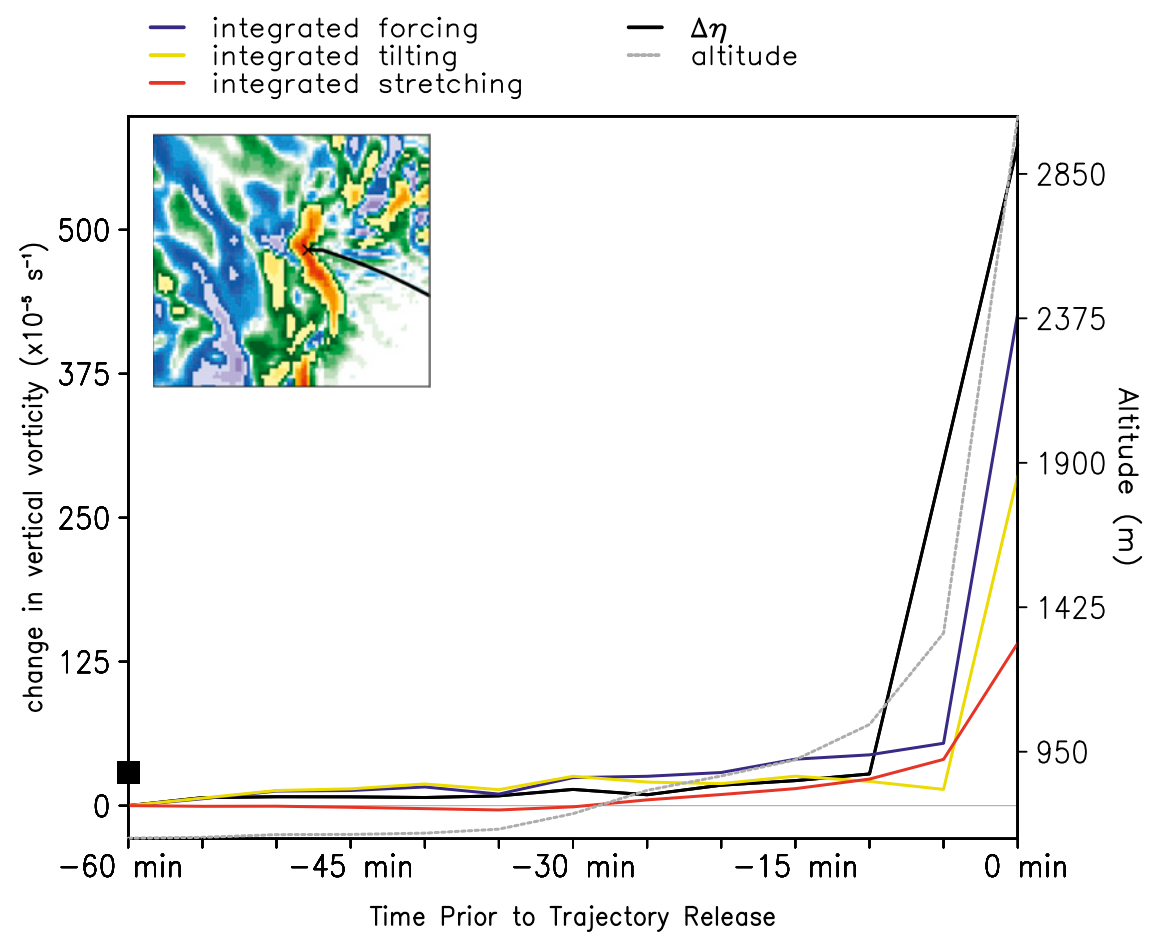

FIG. 8. As in Fig. 6, but for a representative backward trajectory released at $700 \mathrm{hPa}$ at 0830 UTC within the ascent-driven tilting trajectory population.

\section{2) ASCENT-DRIVEN TILTING}

Of the 13 trajectories constituting the ascent-driven tilting trajectory population, 3 (all at $700 \mathrm{hPa}$ ) were released from the vertical vorticity maximum itself while $10(7$ at $700 \mathrm{hPa}$ and 3 at $925 \mathrm{hPa}$ ) were released immediately adjacent to the vertical vorticity maximum. A representative backward trajectory from this population is depicted within Fig. 8. Of the 13 trajectories constituting this population, 10 evolve similarly to Fig. 8 , whereas the other 3 exhibit a more complicated forcing pattern.

Backward trajectories within this population ascending to either 925 or $700 \mathrm{hPa}$ originate within the boundary layer to the south and east, in the storm-relative sense, of the MCS within a streamwise horizontal vorticity-rich environment. Many backward trajectories within this trajectory population, including that displayed in Fig. 8, are characterized by weakly cyclonic initial vertical vorticity, which we hypothesize is associated with the zonally oriented baroclinic zone along which these trajectories originate (e.g., Figs. 1 and 5). However, it is unclear why backward trajectories within the ascent-driven stretching population would not also exhibit similar characteristics.

Vertical vorticity is initially generated by the updraftinduced tilting of streamwise vorticity, particularly within the $0-15 \mathrm{~min}$ prior to backward trajectory release time. Subsequent along-trajectory vertical vorticity amplification is primarily due to continued updraft-induced tilting.
Vortex tube stretching generally contributes to forcing for increased vertical vorticity; however, the magnitude of such forcing is less than that from tilting. This vertical vorticity forcing evolution is consistent with air parcels containing substantial streamwise vorticity that terminate slightly upstream of a local-ascent maximum along a horizontal gradient of vertical motion, as can be inferred from Fig. 7. Note also that the ascent-driven tilting of environmental streamwise vorticity is a common forcing evolution for backward trajectories released along the leading edge of, rather than within, the parent MCS's squall line (not shown).

\section{3) Descent-Dominant Tilting}

Of the 15 trajectories constituting the descent-dominant tilting trajectory population, 4 were released from the vertical vorticity maximum itself while 11 were released immediately adjacent to the vertical vorticity maximum. Trajectories within this population exhibit a common storm-relative path, descending to their release point from the north and northwest within the $20-30 \mathrm{~min}$ prior to trajectory release time, and acquire cyclonic vertical vorticity primarily via tilting processes. It should be noted that this evolution is independent of trajectory release time.

An example backward trajectory from the descentdominant tilting population is presented in Fig. 9. These 


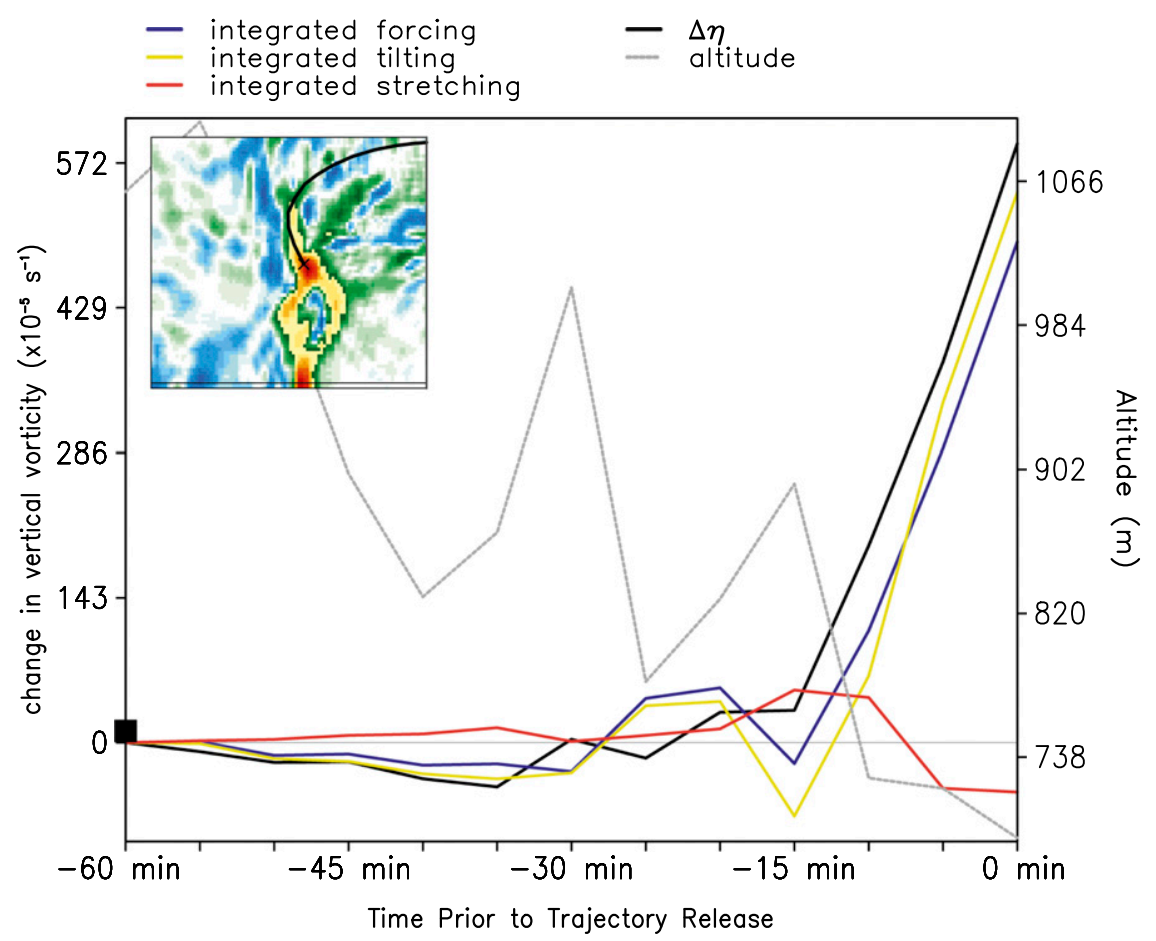

FIG. 9. As in Fig. 6, but for a representative backward trajectory released at $925 \mathrm{hPa}$ at 0845 UTC within the descent-dominant tilting trajectory population.

trajectories descend, albeit in a turbulent fashion, by $500-2000 \mathrm{~m}$. Trajectories within this population begin with near-zero vertical vorticity and acquire cyclonic vertical vorticity primarily through the downdraft tilting of horizontal vorticity. The temporally integrated tilting forcing is generally positive, whereas the temporally integrated stretching forcing is comparatively small in magnitude. These characteristics are indicative of backward trajectories that remain primarily-albeit perhaps not exclusively, given the inferred turbulent vertical motions along the trajectory path-along horizontal gradients of descent in an environment characterized largely by crosswise vorticity of both local and external origins (e.g., Figs. 1 and 2). This descent appears to be linked to persistent simulated regions of lower-tropospheric descent north and west of the convective cell at the northern end of the simulated MCS (not shown) that are akin to the forwardand rear-flank downdrafts, respectively, observed with supercell thunderstorms in westerly vertical wind shear.

\section{Results: Circulation budget analysis}

\section{a. Assessment of circulation evolution and budget balance}

The area-averaged absolute vorticity within the analysis box and its time-integrated change are depicted in Figs. 10a,b. Positive values reflect the presence (Fig. 10a) or increase (Fig. 10b) of cyclonic absolute vorticity. Initially weak cyclonic flow steadily amplifies at all levels between 0600 and 1300 UTC. The greatest amplification is noted between 875 and $600 \mathrm{hPa}$, which is consistent with a warm-core vortex structure. Cyclonic flow weakens after $1500 \mathrm{UTC}$, particularly below $700 \mathrm{hPa}$, as the vortex moves eastward into the Ohio River valley.

Next, the balance between the predicted and simulated temporal change of area-averaged absolute vorticity is assessed (Fig. 11). Below $850 \mathrm{hPa}$, the predicted change is consistently greater than the simulated change (Fig. 11c). This is likely due to the neglect of friction. Above $850 \mathrm{hPa}$, the greatest discrepancies between the predicted and simulated change occur between 0800 and 1200 UTC. It is hypothesized that the neglect of numerical diffusion within the budget and sensitivity in the analysis to the simulated vortex motion estimate lead to these discrepancies. To large extent, however, there exists good qualitative and quantitative agreement between the predicted and simulated temporal change of area-averaged absolute vorticity, lending confidence in using the circulation budget output to examine the formation and evolution of the simulated vortex.

\section{b. Physical interrogation of budget output}

The instantaneous contributions of the dominant forcing terms to changes in area-averaged absolute vorticity are 

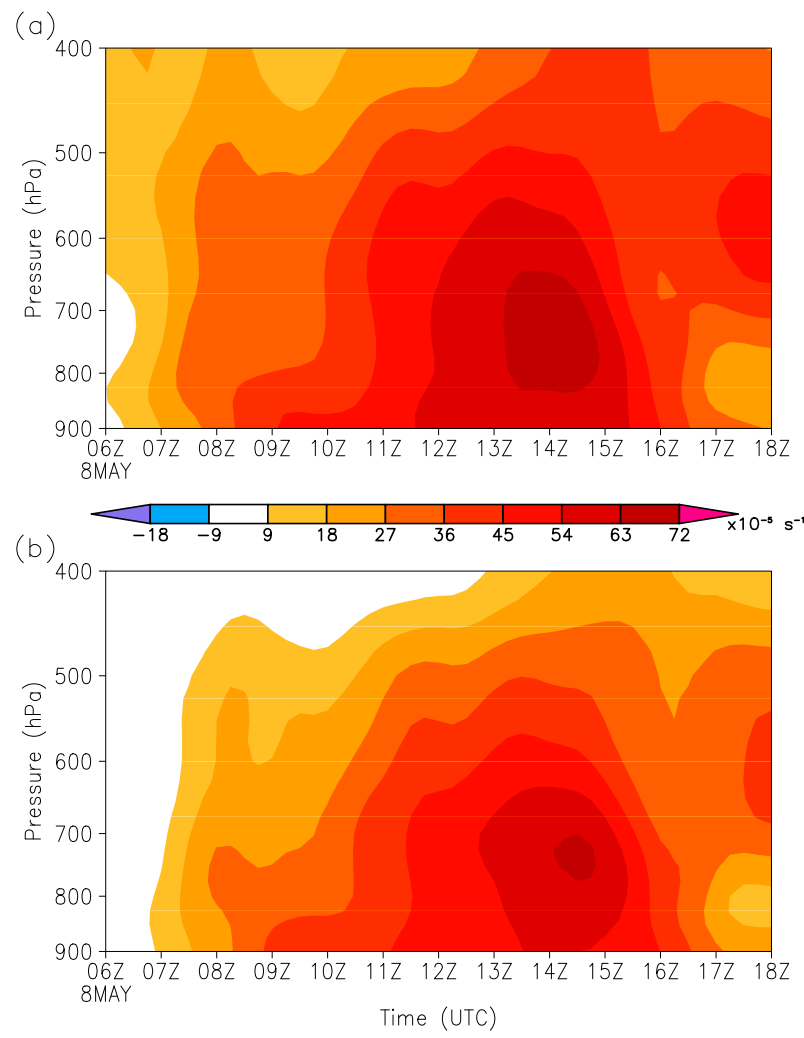

FIG. 10. (a) Area-averaged absolute vorticity $\bar{\eta}$ and (b) the instantaneous difference in area-averaged absolute vorticity from that at 0600 UTC 8 May 2009, defined as $\bar{\eta}(t)$ minus $\bar{\eta}(t=0)$. All fields are presented between 0600 and 1800 UTC 8 May 2009 and between 900 and $400 \mathrm{hPa}$. The units in each panel are $\times 10^{-5} \mathrm{~s}^{-1}$.

depicted in Fig. 12. To first order, the mean transport of mean planetary vorticity (Fig. 12a), the mean transport of mean relative vorticity (Fig. 12b), and the eddy transport of perturbation relative vorticity (Fig. 12d) contribute to increased area-averaged lower- to middletropospheric cyclonic absolute vorticity, particularly prior to 1400 UTC. Conversely, vortex-scale tilting (Fig. 12c) contributes to decreased area-averaged lower- to middletropospheric cyclonic absolute vorticity. The magnitudes of these terms are maximized between 700 and $750 \mathrm{hPa}$ for the mean transport terms and below $800 \mathrm{hPa}$ for the eddy transport and tilting terms. In the middle to upper troposphere, vortex-scale tilting contributes to increased area-averaged cyclonic absolute vorticity, whereas the eddy transport of perturbation relative vorticity contributes to decreased area-averaged cyclonic absolute vorticity throughout much of the analysis period. These insights are all supported by an analysis of the temporally integrated contributions of each forcing term to changes in area-averaged absolute vorticity (Fig. 13).

We next seek to physically describe the contributors to each forcing. Increased area-averaged cyclonic absolute

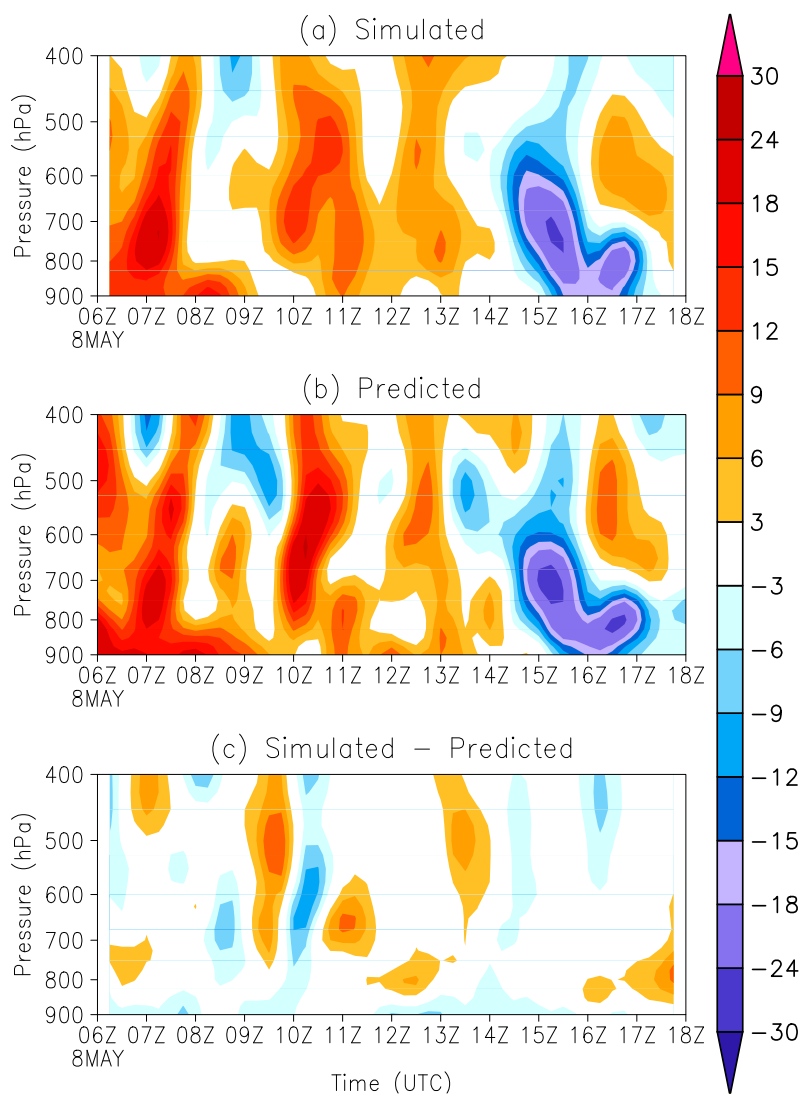

FIG. 11. The (a) simulated temporal change of area-averaged absolute vorticity computed from $d C / d t$; (b) predicted temporal change of area-averaged absolute vorticity, computed from the sum of all forcing terms in (3); and (c) residual between (a) and (b). In (c), negative (positive) values indicate that the predicted areaaveraged absolute vorticity tendency is more (less) cyclonic than the simulated area-averaged absolute vorticity tendency. All fields are for $0600-1800$ UTC 8 May 2009 and $900-400 \mathrm{hPa}$. The units in each panel are $\times 10^{-5} \mathrm{~s}^{-1} \mathrm{~h}^{-1}$.

vorticity due to the mean transport of planetary vorticity (Fig. 12a) is uniquely identifiable with convergent flow into the analysis box. Early in the MCS's life cycle, the convergent flow is primarily associated with the intersection of the low-level jet, trailing dryline, and the zonally oriented, lower- to middle-tropospheric baroclinic zone across southern Kansas, each as illustrated by Fig. 10 of Weisman et al. (2013). As the MCS matures, convergence becomes predominantly driven by the convergent flow, associated with the nascent meso- $\beta$-scale vortex itself (not shown), which weakens in magnitude as the vortex matures and becomes rotation dominant. The inferred vertical profile of convergence implies a stratiform heating profile, peaked at around $700 \mathrm{hPa}$, similar to that observed with the formation of MCVs (e.g., Raymond and Jiang 1990).

Increased area-averaged cyclonic absolute vorticity due to the mean transport of relative vorticity (Fig. 12b) 

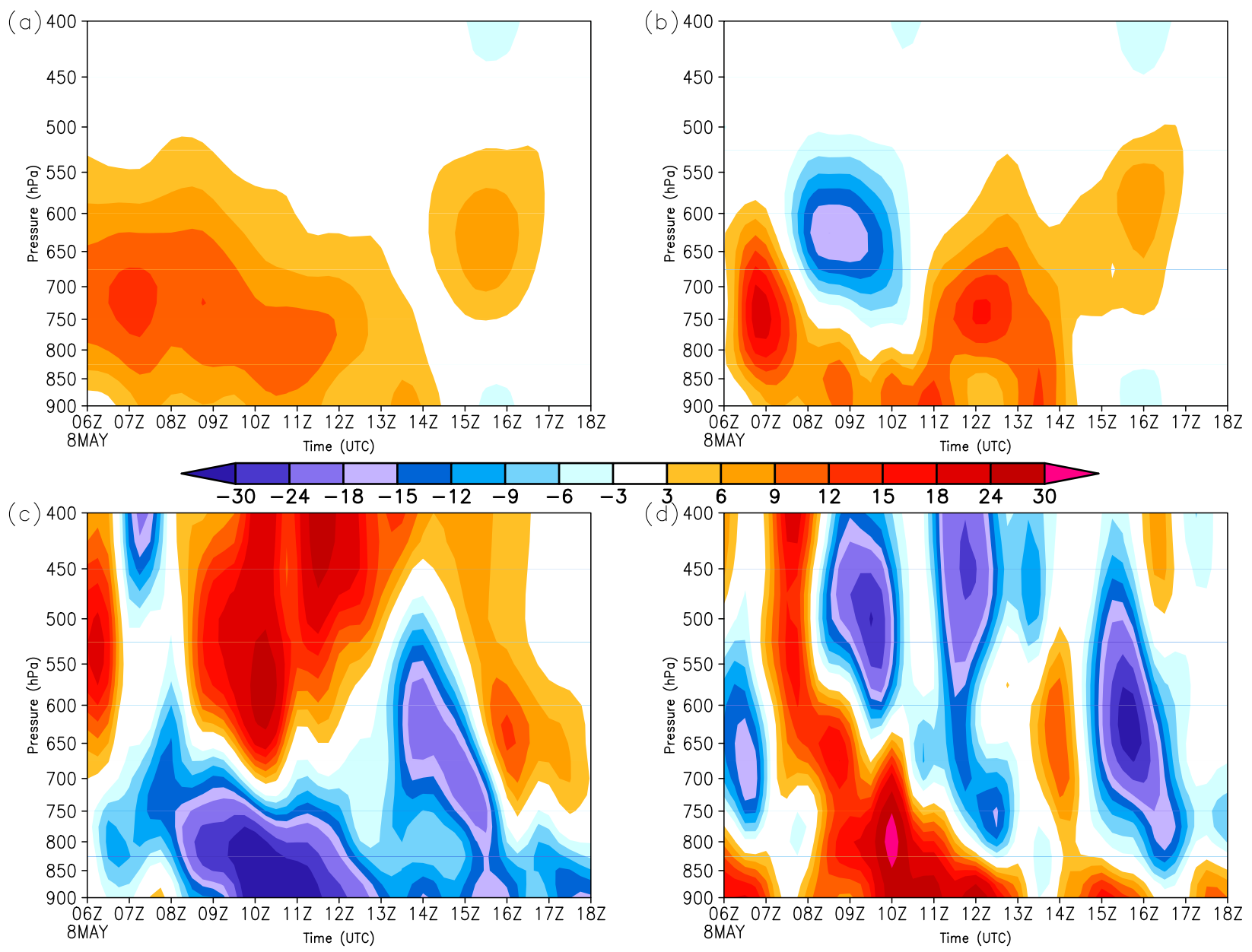

FIG. 12. Forcing of the temporal change in area-averaged absolute vorticity due to the (a) stretching of mean planetary vorticity, (b) stretching of mean relative vorticity, (c) tilting of horizontal vorticity, and (d) eddy transport of perturbation relative vorticity. Positive values of each field indicate forcing for increased cyclonic area-averaged absolute vorticity and, by extension, circulation. All fields are for 0600-1800 UTC 8 May 2009 and 900-400 hPa. The units in each panel are $\times 10^{-5} \mathrm{~s}^{-1} \mathrm{~h}^{-1}$.

is driven primarily by convergent flow prior to 0800 UTC and the presence of large mean cyclonic relative vorticity along the perimeter of the analysis box, presumably associated with the growing vortex itself, between 1100 and 1400 UTC (Fig. 14). Conversely, decreased areaaveraged cyclonic absolute vorticity due to the mean transport of relative vorticity in the 700-500-hPa layer between 0800 and 1000 UTC results from the convergence of mean anticyclonic relative vorticity (Fig. 14). Anticyclonic relative vorticity generated within the MCS's cold pool, which is bisected by the circulation analysis box between 0800 and 1000 UTC, appears to be the primary contributor to the box-edge-averaged anticyclonic relative vorticity in the 700-500-hPa layer (Fig. 3b).

To better assess its physical underpinnings, the line integral for the eddy transport term in (4) is decomposed into its components along each side of the analysis box; that is,

$$
\begin{aligned}
-\oint s^{\prime} \mathbf{v}^{\prime} \cdot \mathbf{n} d l= & \sum_{\text {west }} u^{\prime} \zeta^{\prime} \Delta y+\sum_{\text {south }} v^{\prime} \zeta^{\prime} \Delta x \\
& -\sum_{\text {east }} u^{\prime} \zeta^{\prime} \Delta y \sum_{\text {north }} v^{\prime} \zeta^{\prime} \Delta x
\end{aligned}
$$

where $\Delta x=\Delta y=3 \mathrm{~km}$.

As might be expected given its inherently local nature, the forcing is typically maximized over short durations. On the north (Fig. 15a), east (Fig. 15b), and west (Fig. 15d) sides of the analysis box, the forcing is primarily maximized above $800 \mathrm{hPa}$. In the temporal integration, eddy transport along the north and west sides of the analysis box contributes to weakly decreasing circulation. Conversely, on the east side of the analysis box, offsetting forcing for increased (0800-1100 UTC) and decreased (1100-1400 UTC) circulation contributes to a near-zero change in circulation through the period of vortex 

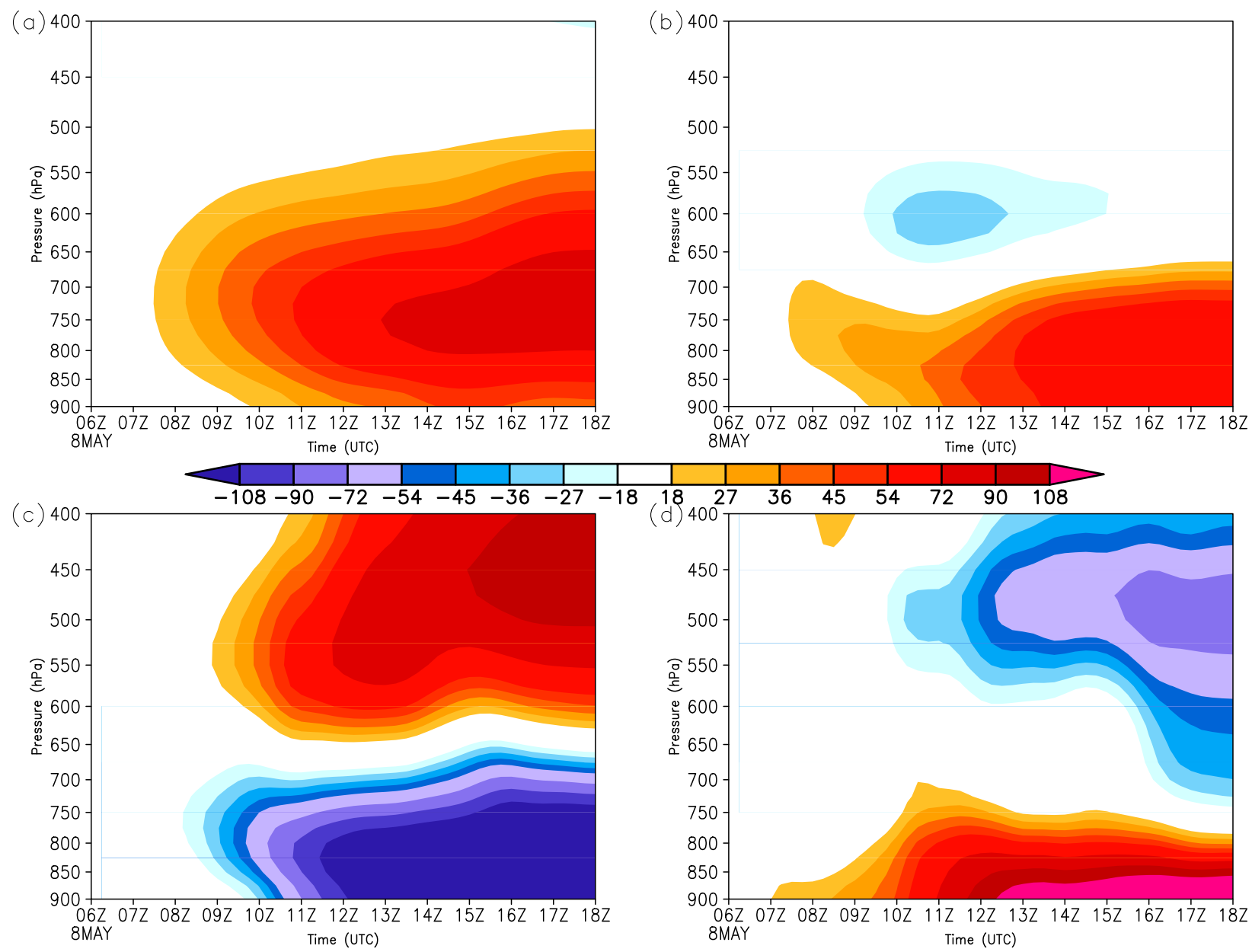

FIG. 13. As in Fig. 12, but for the temporally integrated contribution from each forcing term.

development. This implies that the local (or eddy) import of relative vorticity along the zonally oriented baroclinic zone ahead of the MCS is not the primary contributor to increased circulation as the meso- $\beta$-scale vortex develops.

However, the evolution is substantially different along the south side of the analysis box (Fig. 15c). Persistent forcing for increased circulation is found below $550 \mathrm{hPa}$ between 0800 and $1300 \mathrm{UTC}$ and is maximized below $850 \mathrm{hPa}$ between 0930 and 1300 UTC. The forcing for increased circulation in the lower troposphere is manifest by the expulsion of anticyclonic relative vorticity (generated via tilting within the system's cold pool; not shown) by the diffluent rear-inflow jet trailing the MCS (Fig. 16). This forcing wanes by 1300 UTC as anticyclonic relative vorticity generation within the cold pool ceases owing to the weakening of the cold pool (Weisman et al. 2013).

To better assess its physical underpinnings, the line integral for the tilting term in (4) is also decomposed into its components along each side of the analysis box:

$$
\begin{aligned}
\oint \omega\left(\mathbf{k} \times \frac{\partial \mathbf{v}}{\partial p}\right) \cdot \mathbf{n} d l= & \sum_{\text {west }} \omega \frac{\partial v}{\partial p} \Delta y-\sum_{\text {south }} \omega \frac{\partial u}{\partial p} \Delta x \\
& -\sum_{\text {east }} \omega \frac{\partial v}{\partial p} \Delta y+\sum_{\text {north }} \omega \frac{\partial u}{\partial p} \Delta x .
\end{aligned}
$$

For the tilting term to result in a change in circulation within the analysis box, there must be a box-scale horizontal change in vertical motion and/or the vertical shear of the edge-parallel horizontal wind.

After 0700 UTC, tilting along the north (Fig. 17a), south (Fig. 17c), and west (Fig. 17d) sides of the analysis box contributes to increased middle- to upper-tropospheric circulation. This forcing is offset slightly by forcing for decreased circulation on the east (Fig. 17b) side of the analysis box. In the lower troposphere, tilting along the north, east, and particularly west sides of the analysis box contributes to decreased circulation. There is little 


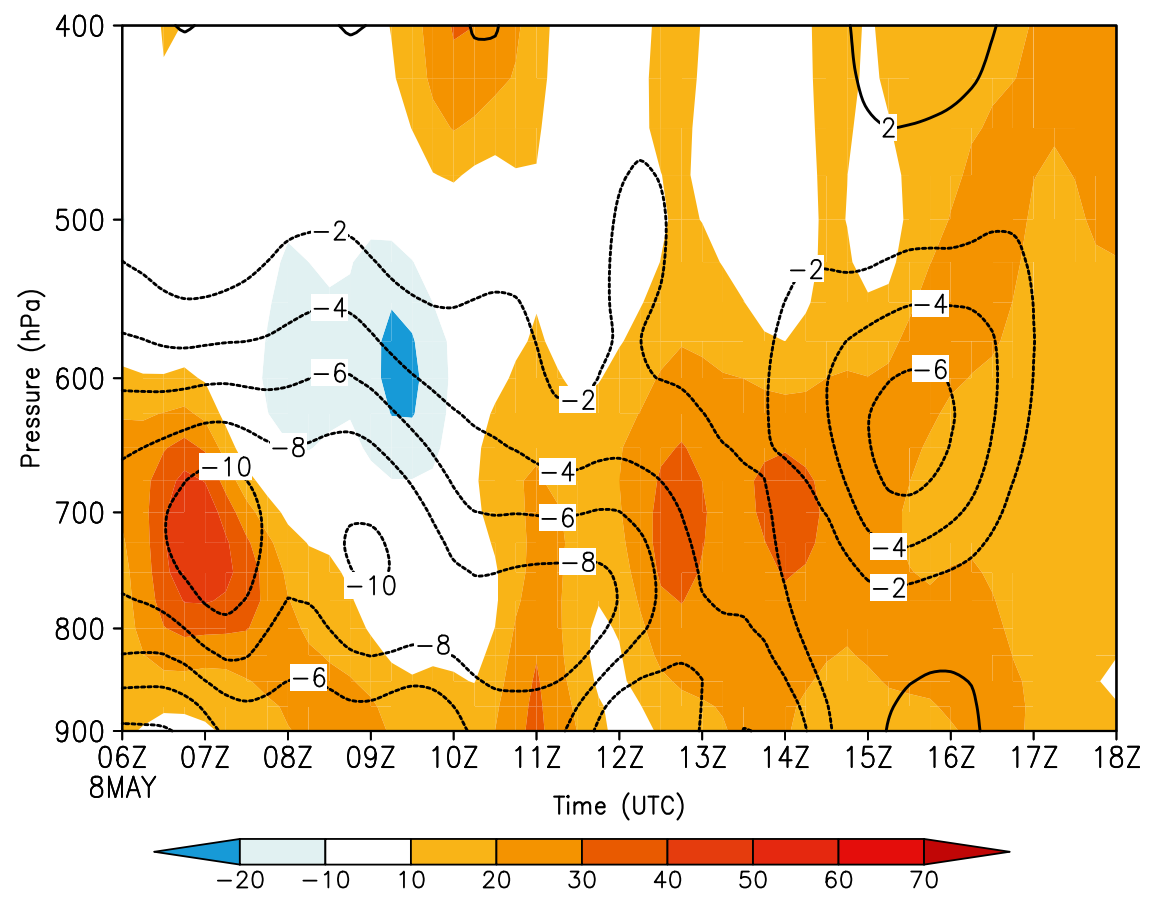

FIG. 14. Circulation analysis box perimeter-averaged absolute vorticity (color shaded; $\times 10^{-5} \mathrm{~s}^{-1}$ ) and perimeter-averaged box-normal wind (contours; $\mathrm{m} \mathrm{s}^{-1}$, negative values denote inward-directed flow) for 0600-1800 UTC 8 May 2009 and 900-400 hPa.

contribution due to tilting along the south side of the analysis box. As substantial local variability exists in the correlation between vertical velocity and vertical wind shear along each edge of the analysis box, we emphasize describing the physical underpinnings behind the forcing at a representative time, 1000 UTC, during the vortex formation period (Fig. 18).

Forcing for increased circulation above $700 \mathrm{hPa}$ on the north side of the analysis box is associated with ascent and westerly vertical wind shear (Fig. 18a). Ascent results primarily from convective-scale updrafts intersecting the north side of the analysis box between 0900 and 1300 UTC (Fig. 3). Westerly vertical wind shear is associated primarily with the background synoptic-scale flow (e.g., Fig. 6d of Weisman et al. 2013). Forcing for increased circulation above $700 \mathrm{hPa}$ on the south side of the analysis box is associated with ascent and easterly vertical wind shear (Fig. 18c). Ascent is associated with the rearward-tilted updraft along the MCS's squall line. Easterly vertical wind shear is consistent with that associated with the rear-inflow jet and the nascent vortex's rotational flow (not shown). Forcing for increased circulation above $500 \mathrm{hPa}$ on the west side of the analysis box is associated with weak ascent and southerly vertical wind shear (Fig. 18d). Southerly vertical wind shear is due to the backing of the horizontal wind field, from the west-northwest at and below $500 \mathrm{hPa}$, as associated with the MCS's rear-inflow jet, to the west-southwest above $500 \mathrm{hPa}$, as associated with the larger-scale environment in which the MCS is embedded. Ascent is hypothesized to be associated primarily with the system-scale ascending front-to-rear flow (not shown).

Forcing for decreased circulation below $500 \mathrm{hPa}$ on the east side of the analysis box is associated with ascent and southerly vertical wind shear (Fig. 18b). Southerly vertical wind shear is associated with the low-level jet [e.g., Figs. 12b,e and 15b,e of Weisman et al. (2013)]. Ascent results from convective-scale updrafts intersecting the east side of the analysis box between 0900 and 1200 UTC (e.g., Fig. 3) and mesoscale ascent associated with the upward-sloping low-level jet (as inferred from Fig. 18b). Forcing for decreased circulation below $750 \mathrm{hPa}$ on the west side of the analysis box is associated with weak descent and southerly vertical wind shear (Fig. 18d). Southerly vertical wind shear is consistent with warm-core vortex rotation. Descent is hypothesized to be associated primarily with the descending rear-inflow jet (not shown).

\section{Conclusions}

In this study, the dynamical processes contributing to warm-core meso- $\beta$-scale vortex formation with the 8 May 2009 "super derecho" have been examined utilizing two 
(a) north
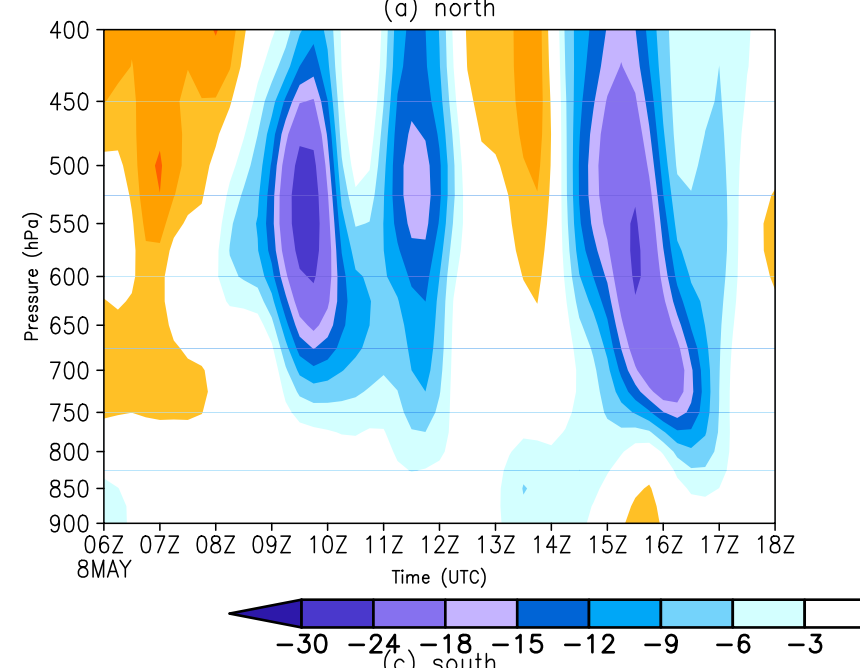

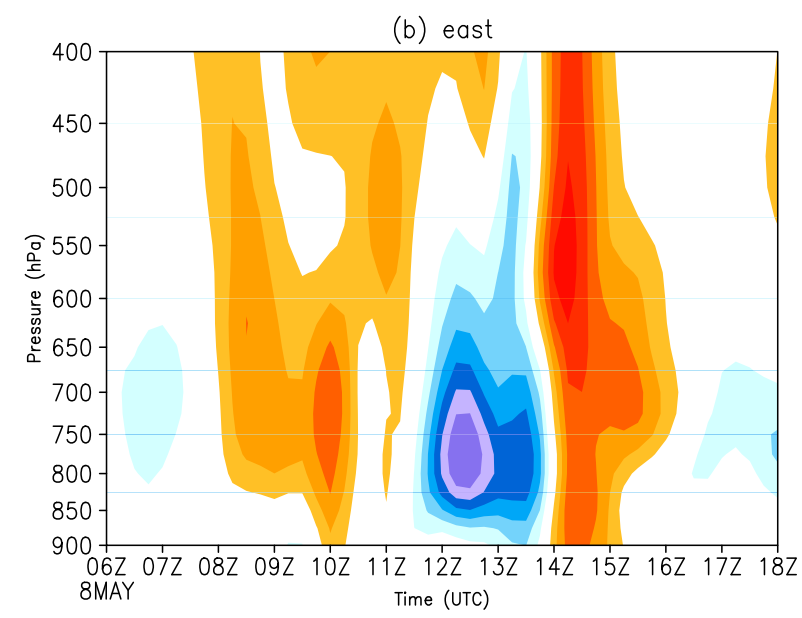

(b) east
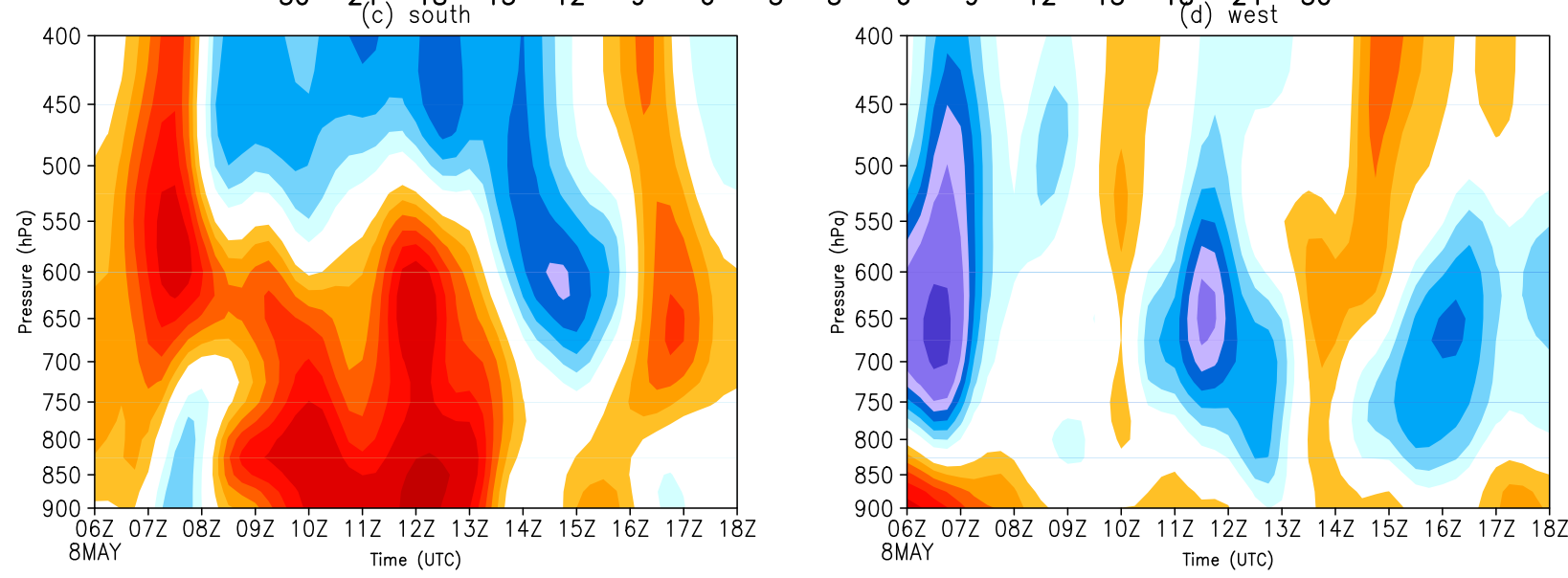

FIG. 15. As in Fig. 12d, but for the contribution to the total eddy transport of perturbation relative vorticity from only the (a) north, (b) east, (c) south, and (d) west side of the analysis box. All fields are for 0600-1800 UTC 8 May 2009 and 900-400 hPa. The units in each panel are $\times 10^{-5} \mathrm{~s}^{-1} \mathrm{~h}^{-1}$.

complementary yet conceptually distinct approaches: a circulation budget and backward trajectory analyses. The former describes how circulation increases on mesoscale spatiotemporal scales but does not describe how vertical vorticity is organized within the circulation region, whereas the latter illuminates the initial source(s) of vertical vorticity (or lack thereof) and describes the convective-scale generation and amplification of cyclonic vertical vorticity.

On the convective scale, most inflowing trajectories originate within the streamwise vorticity-rich boundary layer environment along and south of the zonally oriented baroclinic zone along which the derecho and meso- $\beta$-scale vortex form and traverse (Fig. 5). Many inflowing trajectories contain no initial vertical vorticity; however, those that do generally contain weak cyclonic vertical vorticity that we hypothesize is associated with the baroclinic zone itself (e.g., Figs. 1 and 5). Cyclonic vertical vorticity is primarily generated through updraftinduced tilting and amplified by updraft-induced stretching, which is consistent with an environment characterized primarily by streamwise horizontal vorticity. However, it should be noted that air parcels approaching the developing meso- $\beta$-scale vortex from the north and west acquire cyclonic vertical vorticity primarily through the descent-induced tilting of lower-tropospheric crosswise vorticity.

Cyclonic circulation on the scale of the warm-core meso- $\beta$-scale vortex increases in the lower troposphere in response to the mean convergence of cyclonic absolute vorticity and the local expulsion of eddy anticyclonic vertical vorticity generated within the MCS's cold pool. The former is associated with both synoptic-scale and vortex-scale forcing and is consistent with the findings of numerous previous investigations into line-end vortex and MCV formation and amplification (e.g., 
(a) 09Z08MAY2009

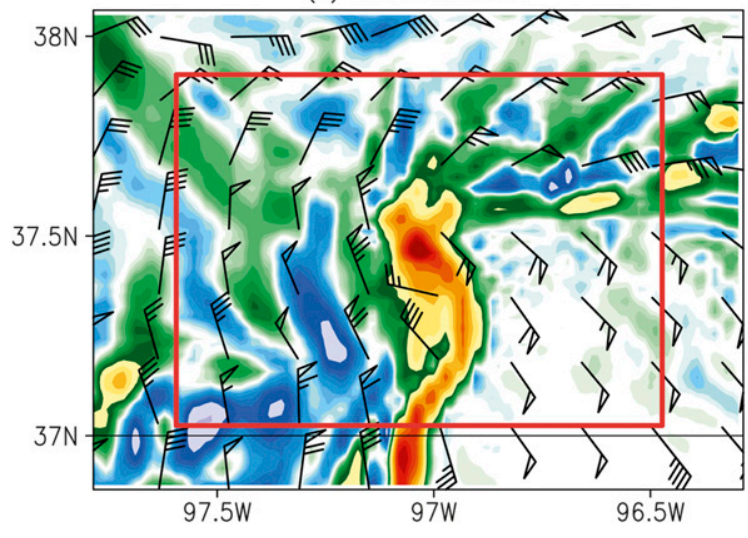

(b) 10Z08MAY2009

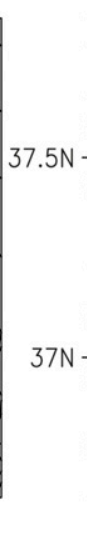

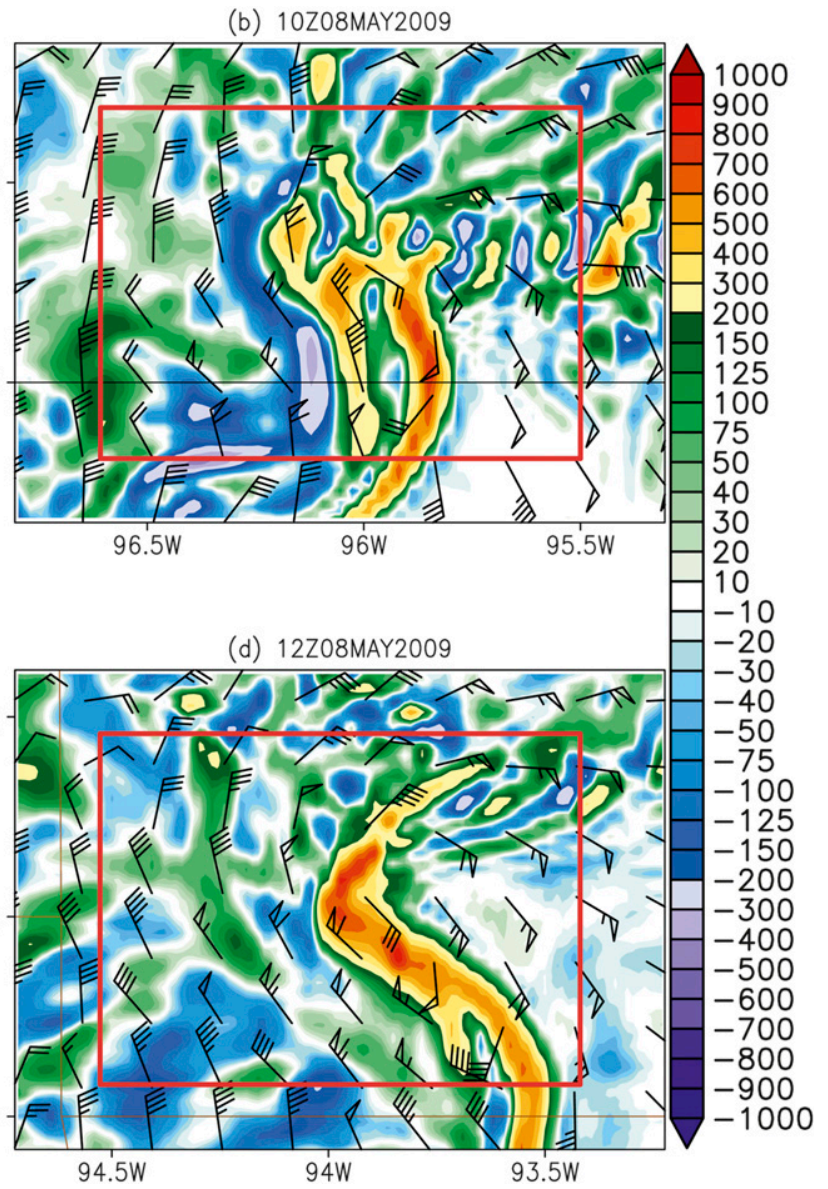

(c) 11Z08MAY2009
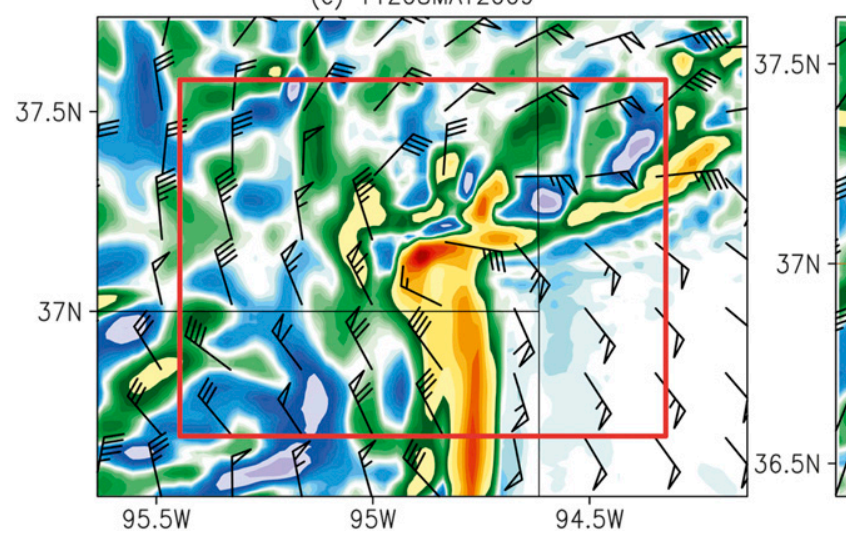

$94.5 \mathrm{~W}$

$93.5 \mathrm{~W}$

FIG. 16. Simulated 850-hPa relative vorticity (color shaded; $\times 10^{-5} \mathrm{~s}^{-1}$ ) and storm-relative wind (half barb: $2.5 \mathrm{~m} \mathrm{~s}^{-1}$, full barb: $5 \mathrm{~m} \mathrm{~s}{ }^{-1}$, flag: $25 \mathrm{~m} \mathrm{~s}^{-1}$ ) valid at (a) 0900, (b) 1000, (c) 1100, and (d) 1200 UTC 8 May 2009. The $100 \mathrm{~km} \times 100 \mathrm{~km}$ control analysis box at each time is depicted by the red square. The storm-relative wind at each time is computed with respect to a constant-storm-motion estimate of $(20,-2) \mathrm{ms}^{-1}$.

Weisman and Davis 1998; Yu et al. 1999; Trapp and Weisman 2003; Conzemius and Montgomery 2009; Davis and Galarneau 2009). The latter is driven by the diffluent, outward-directed lower-tropospheric flow associated with the MCS's descending rear-inflow jet. System-scale tilting of horizontal vorticity associated with the lowlevel jet, rear-inflow jet, environmental vertical wind shear, and rotational flow of the warm-core vortex contributes to reduced cyclonic circulation within the lower troposphere while contributing to increased cyclonic circulation in the middle to upper troposphere.

The circulation budget and backward trajectory analyses each highlight the importance of lower- to middletropospheric convergence to cyclonic vertical vorticity amplification on the convective to vortex scale. Conversely, an apparent contradiction exists between the two analysis methods with respect to tilting's contribution to changes in cyclonic vertical vorticity. On the convective scale, tilting is identified with cyclonic vertical vorticity generation because the tilted horizontal vorticity is streamwise in nature. As illuminated by the circulation budget analysis, anticyclonic vertical vorticity generated on the convective scale by the tilting of streamwise horizontal vorticity is ameliorated by the mesoscale convergence of planetary vorticity (e.g., Weisman and Davis 1998; Trapp and Weisman 2003). On the vortex scale, tilting is identified with forcing for decreased cyclonic vertical vorticity in the lower troposphere. Again, mesoscale convergence of planetary vorticity counterbalances this forcing. Consequently, we argue that the joint interrogation of circulation budget and backward trajectory output provides internally consistent insight into the multiscale dynamical processes crucially important to the cyclonic vertical vorticity generation and amplification with this case.

Convergence extending down to the surface (e.g., Fig. 14) and acting on both vortex-scale planetary and relative vertical vorticity contributes to meso- $\beta$-scale 
(a) north
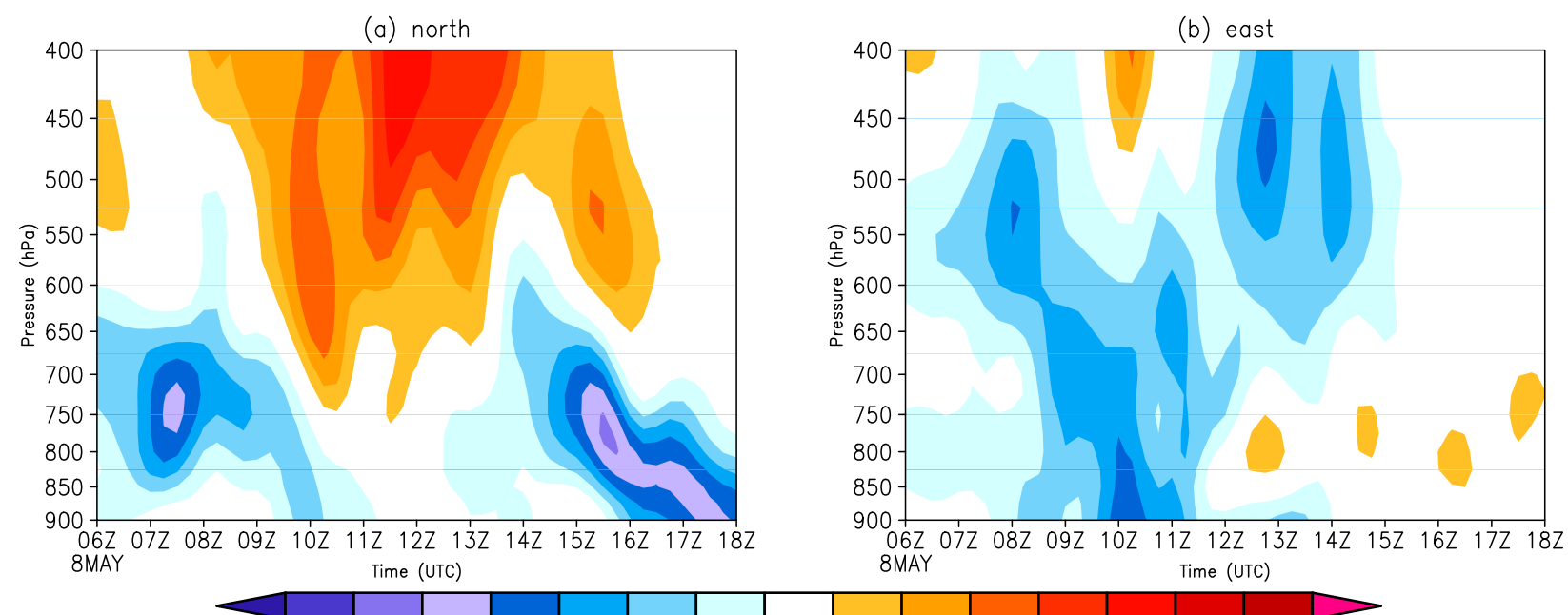
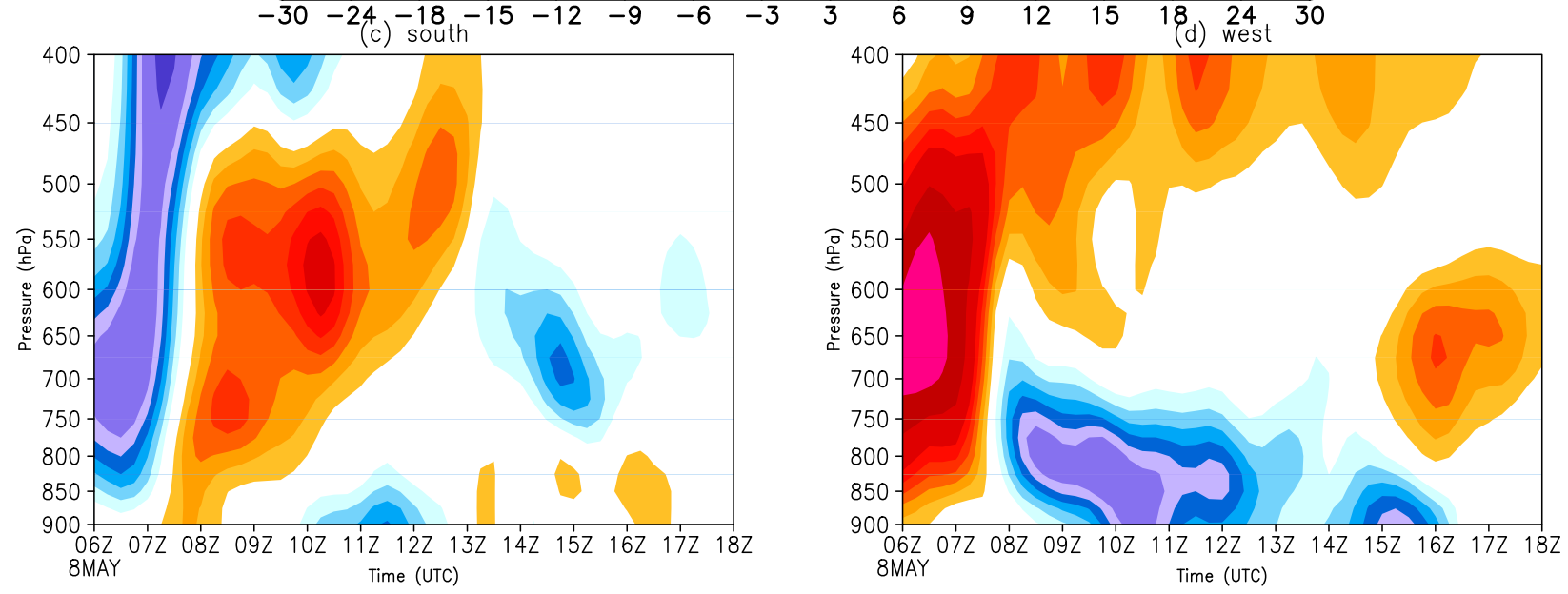

FIG. 17. As in Fig. 12c, but for the contribution to the total tilting from only the (a) north, (b) east, (c) south, and (d) west side of the analysis box. All fields are for 0600-1800 UTC 8 May 2009 and 900-400 hPa in the vertical. The units in each panel are $\times 10^{-5} \mathrm{~s}^{-1} \mathrm{~h}^{-1}$.

vortex development within the boundary layer. A moist, potentially stable near-vortex environment, particularly between 1000 and 1300 UTC (Fig. 4), promotes this vertical profile of convergence and, consequently, systemscale vortex stretching (e.g., Davis and Galarneau 2009). This is consistent with previous studies that have demonstrated that a moist neutral boundary layer is a necessary condition for near-surface rotation to develop beneath a middle-tropospheric MCV, as discussed in section 1 . The presence of a moist boundary layer is not an atypical occurrence in association with MCSs or derechos. However, the presence of abundant moisture throughout the troposphere is somewhat atypical, as noted by Coniglio et al. (2011), and is more commonly observed with tropical cyclones and MCVs with lower-tropospheric cyclonic rotation. Similarly, it should also be emphasized that the presence of a derecho along a baroclinic zone is not atypical (e.g., Coniglio et al. 2004), but its presence along a baroclinic zone in a deeply moist environment is somewhat atypical and is more reminiscent of the "tropical transition" or "low-level baroclinic" tropical cyclone development paradigms of McTaggart-Cowan et al. (2008).

In isolation, each of the aforementioned physical processes and the environmental conditions in which they occur are not atypical for derecho formation (Coniglio et al. 2011; Weisman et al. 2013). Rather, we argue that the combination of elements seen with this case is less typical and helps to explain why such an intense, warmcored vortex formed with this event but not with other severe, derecho-producing MCS events. With the exception of stronger vertical wind shear in this case, noteworthy similarities in the thermodynamic environment and vertical vorticity generation mechanisms exist between the warm-core meso- $\beta$-scale vortex studied herein and tropical cyclones. However, there also exist similarities in the vertical vorticity generation mechanisms between this case and MCVs (whether or not they exhibit near-surface rotation), leading-line mesovortices, 
(a) north

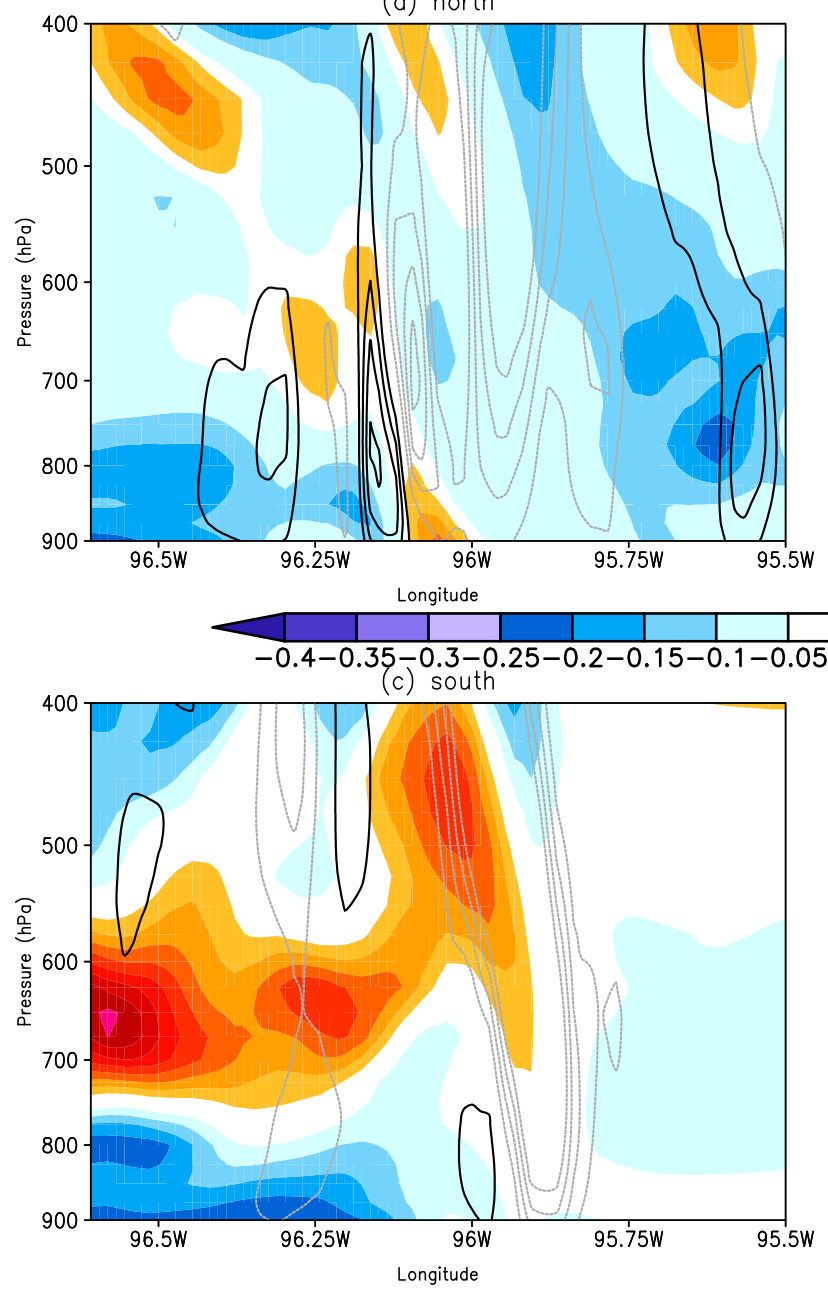

(b) east

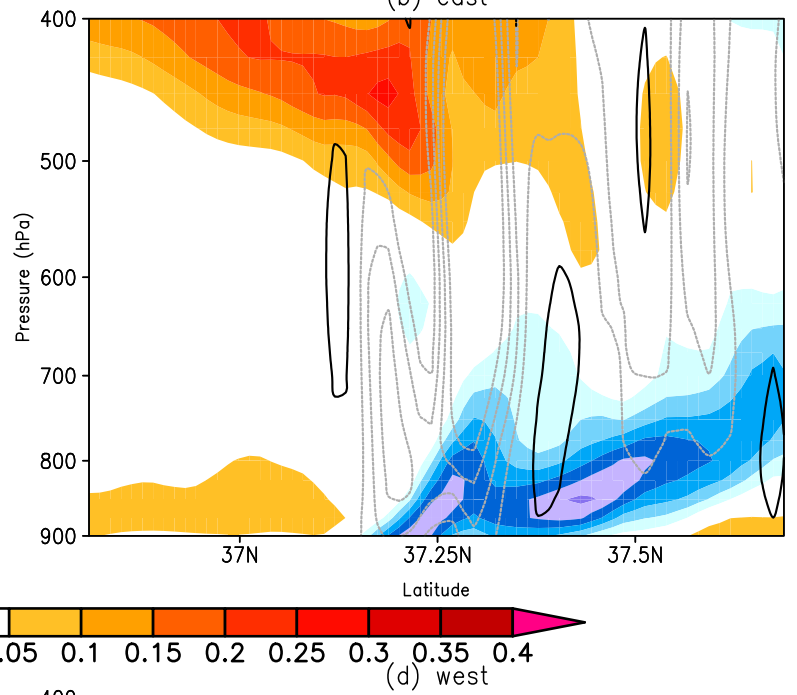

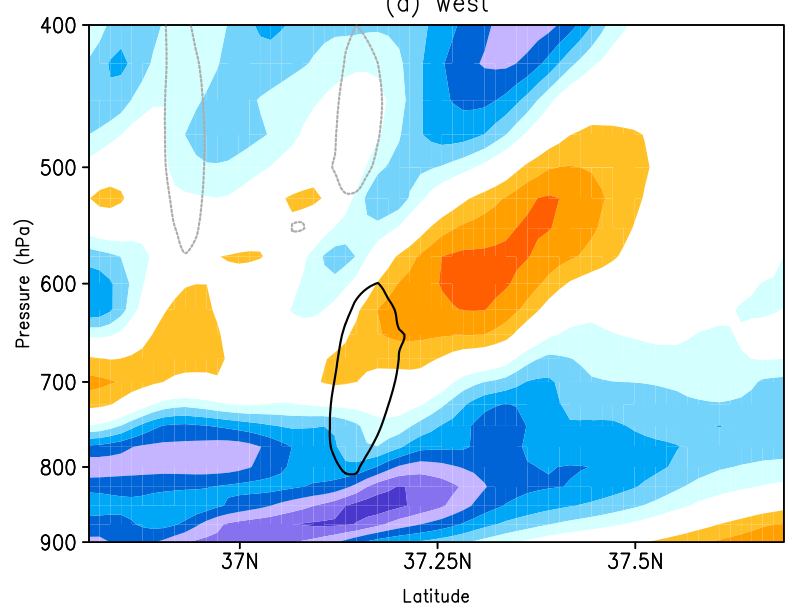

FIG. 18. Vertical cross sections between $900-400 \mathrm{hPa}$ of vertical wind shear $\left(\mathrm{m} \mathrm{s}^{-1} \mathrm{hPa}^{-1}\right.$; color shaded $)$ and omega $\left(\mathrm{Pa} \mathrm{s}^{-1}\right.$; contours at $\pm 10,20,30$, and $40 \mathrm{~Pa} \mathrm{~s}^{-1}$ with negative values in gray) at $1000 \mathrm{UTC}$ on the (a) north, (b) east, (c) south, and (d) west sides of the circulation analysis box. Positive values of vertical wind shear on the north and south (east and west) sides of the analysis box indicate easterly (northerly) vertical wind shear. Forcing for increased circulation within the analysis box occurs when omega and vertical wind shear are of like (opposite) sign on the west and north (east and south) sides of the analysis box. All fields are averaged within \pm 5 model grid points north and south (east and west) of the control location of the north and south (east and west) sides of the analysis box.

and supercell thunderstorms. Therefore, it appears that the warm-core meso- $\beta$-scale vortex studied herein does not fit neatly into one location along the broad spectrum of rotating mesoscale phenomena but rather straddles a large portion of this spectrum. Further research utilizing climatological and idealized modeling approaches is necessary to illuminate the commonality of the combination of physical processes and environmental conditions that supported the development of an intense, warm-core meso- $\beta$-scale vortex and how this combination impacted vortex intensity.

The real-time numerical simulation of the 8 May 2009 derecho event utilized herein and by Weisman et al. (2013) was fortuitous. However, the ability to replicate an event with an individual numerical simulation does not necessarily imply that the event is practically or intrinsically predictable in nature. Additional simulations of this event demonstrate that the basic result-that of warm-core meso- $\beta$-scale vortex formation-is fairly insensitive to small deviations in horizontal grid spacing and to the physical parameterizations employed within the simulation. However, this basic result is highly sensitive to the representation of the initial and lateral boundary conditions (not shown). Such sensitivity aligns with the findings of Wandishin et al. (2010) and Melhauser and Zhang (2012), who each demonstrated sensitivity in simulated squall line structure to small differences (i.e., less than observational error) in the initial conditions 
used to initialize the model. Further study is necessary, however, to elucidate the precise degree of practical predictability of this and other severe convection events.

Acknowledgments. We acknowledge the assistance of Wei Wang and Kevin Manning in support of the realtime convective forecasting operations that provided the simulation utilized in this study. This manuscript benefitted greatly from discussions with Mike Coniglio, Chris Davis, Tom Galarneau, Rich Rotunno, and Stan Trier. Reviews by Erik Rasmussen and two anonymous reviewers were of great benefit to this manuscript. The first author acknowledges the partial support of an NCAR Advanced Study Program fellowship during the conduct of this research.

\section{REFERENCES}

Atkins, N. T., and M. St. Laurent, 2009: Bow echo mesovortices Part II: Their genesis. Mon. Wea. Rev., 137, 1514-1532.

Bister, M., and K. A. Emanuel, 1997: The genesis of Hurricane Guillermo: TEXMEX analyses and a modeling study. Mon. Wea. Rev., 125, 2662-2682.

Brandes, E. A., 1990: Evolution and structure of the 6-7 May 1985 mesoscale convective system and associated vortex. Mon. Wea. Rev., 118, 109-127.

_ , and C. L. Ziegler, 1993: Mesoscale downdraft influences on vertical vorticity in a mature mesoscale convective system. Mon. Wea. Rev., 121, 1337-1353.

Chen, F., and J. Dudhia, 2001: Coupling an advanced land surfacehydrology model with the Penn State-NCAR MM5 modeling system. Part I: Model implementation and sensitivity. Mon. Wea. Rev., 129, 569-585.

Coniglio, M. C., D. J. Stensrud, and M. B. Richman, 2004: An observational study of derecho-producing convective systems. Wea. Forecasting, 19, 320-337.

_ - S. F. Corfidi, and J. S. Kain, 2011: Environment and early evolution of the 8 May 2009 derecho-producing convective system. Mon. Wea. Rev., 139, 1083-1102.

,-- , and,- 2012 : Views on applying RKW theory: An illustration using the 8 May 2009 derecho-producing convective system. Mon. Wea. Rev., 140, 1023-1043.

Conzemius, R. J., and M. T. Montgomery, 2009: Clarification on the generation of absolute and potential vorticity in mesoscale convective vortices. Atmos. Chem. Phys., 9, 7591-7605.

Dahl, J. M. L., M. D. Parker, and L. J. Wicker, 2012: Uncertainties in trajectory calculations within near-surface mesocyclones of simulated supercells. Mon. Wea. Rev., 140, 2959-2966.

Davis, C. A., and M. L. Weisman, 1994: Balanced dynamics of mesoscale vortices produced in simulated convective systems. J. Atmos. Sci., 51, 2005-2030.

— during BAMEX. Part I: Kinematic and thermodynamic structure. Mon. Wea. Rev., 135, 2029-2049.

_ , and T. J. Galarneau, 2009: The vertical structure of mesoscale convective vortices. J. Atmos. Sci., 66, 686-704.

Dudhia, J., 1989: Numerical study of convection observed during the winter monsoon experiment using a mesoscale twodimensional model. J. Atmos. Sci., 46, 3077-3107.
Dunkerton, T. J., M. T. Montgomery, and Z. Wang, 2009: Tropical cyclogenesis in a tropical wave critical layer: Easterly waves. Atmos. Chem. Phys., 9, 5587-5646.

Fritsch, J. M., J. D. Murphy, and J. S. Kain, 1994: Warm core vortex amplification over land. J. Atmos. Sci., 51, 1780-1807.

Gamache, J. F., and R. A. Houze, 1982: Mesoscale air motions associated with a tropical squall line. Mon. Wea. Rev., 110, 118-135.

Gray, W. M., 1968: Global view of the origin of tropical disturbances and storms. Mon. Wea. Rev., 96, 669-700.

James, E. P., and R. H. Johnson, 2010: Patterns of precipitation and mesolow evolution in midlatitude mesoscale convective vortices. Mon. Wea. Rev., 138, 909-931.

Janjic, Z. I., 2001: Nonsingular implementation of the MellorYamada 753 level 2.5 scheme in the NCEP Meso Model. NOAA/NWS/NCEP Office Note 437, 61 pp.

Lese, A. D., and S. Martinaitis, 2010: Observations and quantification of counter-rotating mesovortex couplets within the 8 May 2009 southern Missouri derecho. Preprints, 25th Conf. on Severe Local Storms, Denver, CO, Amer. Meteor. Soc., 3B.3. [Available online at https://ams.confex.com/ams/25SLS/ techprogram/paper_175427.htm.]

McTaggart-Cowan, R., G. D. Deane, L. F. Bosart, C. A. Davis, and T. J. Galarneau Jr., 2008: Climatology of tropical cyclogenesis in the North Atlantic (1948-2004). Mon. Wea. Rev., 136, 1284 1304.

Melhauser, C., and F. Zhang, 2012: Practical and intrinsic predictability of severe and convective weather at the mesoscales. J. Atmos. Sci., 69, 3350-3371.

Menard, R. D., and J. M. Fritsch, 1989: A mesoscale convective complex-generated inertially stable warm core vortex. Mon. Wea. Rev., 117, 1237-1261.

Meng, Z., F. Zhang, P. Markowski, D. Wu, and K. Zhao, 2012: A modeling study on the development of a bowing structure and associated rear inflow within a squall line over South China. J. Atmos. Sci., 69, 1182-1207.

Mlawer, E. J., S. J. Taubman, P. D. Brown, M. J. Iacono, and S. A. Clough, 1997: Radiative transfer for inhomogeneous atmosphere: RRTM, a validated correlated-k model for the longwave. J. Geophys. Res., 102 (D14), 16663-16682.

Montgomery, M. T., M. E. Nicholls, T. A. Cram, and A. B. Saunders, 2006: A vortical hot tower route to tropical cyclogenesis. J. Atmos. Sci., 63, 355-386.

Przybylinski, R. W., J. S. Schaumann, D. T. Cramer, and N. T. Atkins, 2010: The 08 May 2009 Missouri derecho: Radar analysis and warning implications over parts of southwest Missouri. Preprints, 25th Conf. on Severe Local Storms, Denver, CO, Amer. Meteor. Soc., 3B.1. [Available online at https://ams. confex.com/ams/25SLS/techprogram/paper_176095.htm.]

Raymond, D. J., and H. Jiang, 1990: A theory for long-lived mesoscale convective systems. J. Atmos. Sci., 47, 3067-3077.

Rogers, R. F., and J. M. Fritsch, 2001: Surface cyclogenesis from convectively driven amplification of midlevel mesoscale convective vortices. Mon. Wea. Rev., 129, 605-637.

Skamarock, W. C., 2004: Evaluating mesoscale NWP models using kinetic energy spectra. Mon. Wea. Rev., 132, 3019-3032.

— , and M. L. Weisman, 2009: The impact of positive-definite moisture transport on NWP precipitation forecasts. Mon. Wea. Rev., 137, 488-494.

and Coauthors, 2008: A description of the Advanced Research WRF version 3. NCAR Tech. Note NCAR/TN475+STR, 113 pp. [Available online at http://www.mmm.ucar. edu/wrf/users/docs/arw_v3.pdf.] 
Thompson, G., P. R. Field, W. D. Hall, and R. M. Rasmussen, 2006: A new bulk microphysical parameterization for WRF. Extended Abstracts, 7th WRF Users' Workshop, Boulder, Colorado, WRF, 5.3. [Available online at http://www.mmm.ucar. edu/wrf/users/workshops/WS2006/abstracts/Session05/ 5_3_Thompson.pdf.]

Trapp, R. J., and M. L. Weisman, 2003: Low-level mesovortices within squall lines and bow echoes. Part II: Their genesis and implications. Mon. Wea. Rev., 131, 2804-2823.

Wakimoto, R. M., H. V. Murphey, A. Nester, D. P. Jorgensen, and N. T. Atkins, 2006: High winds generated by bow echoes. Part I: Overview of the Omaha bow echo 5 July 2003 storm during BAMEX. Mon. Wea. Rev., 134, 2793-2829.

Wandishin, M. S., D. J. Stensrud, S. L. Mullen, and L. J. Wicker, 2010: On the predictability of mesoscale convection systems: Three-dimensional simulations. Mon. Wea. Rev., 138, 863885.

Weisman, M. L., and C. A. Davis, 1998: Mechanisms for the generation of mesoscale vortices within quasi-linear convective systems. J. Atmos. Sci., 55, 2603-2622.
_ _ and R. J. Trapp, 2003: Low-level mesovortices within squall lines and bow echoes. Part I: Overview and dependence on environmental shear. Mon. Wea. Rev., 131, 2779-2803.

—_, C. Evans, and L. Bosart, 2013: The 8 May 2009 superderecho: Analysis of a real-time explicit convective forecast. Wea. Forecasting, 28, 863-892.

Wheatley, D. M., and R. J. Trapp, 2008: The effect of mesoscale heterogeneity on the genesis and structure of mesovortices within quasi-linear convective systems. Mon. Wea. Rev., 136, 4220-4241.

Yu, C.-K., B. J.-D. Jou, and B. F. Smull, 1999: Formative stage of a long-lived mesoscale vortex observed by airborne Doppler radar. Mon. Wea. Rev., 127, 838-857.

Zhang, D.-L., and J. M. Fritsch, 1987: Numerical simulation of the meso- $\beta$ scale structure and evolution of the 1977 Johnstown flood. Part II: Inertially stable warm-core vortex and the mesoscale convective complex. J. Atmos. Sci., 44, 2593-2612.

, and - 1988: A numerical investigation of a convectively generated, inertially stable, extratropical warm-core mesovortex over land. Part I: Structure and evolution. Mon. Wea. Rev., 116, 2660-2687. 